\title{
CURIA DOMINE - DER HOF DER MARGARETHE MAULTASCH ALS BEISPIEL WEIBLICHER HOFHALTUNG IM SPÄTMITTELALTER
}

Die Analyse von Aufbau und Organisation spätmittelalterlicher und frühneuzeitlicher Fürstenresidenzen, ihre Bedeutung für Landesausbau, Regierung und Verwaltung hat bereits eine lange Forschungstradition ${ }^{1}$ und insbesondere in den letzten Jahrzehnten neue wissenschaftliche Impulse erhalten. Erwähnt seien in diesem Zusammenhang die aus der Schule von Hans Rall hervorgegangenen Arbeiten zum Urkundenwesen, Rat und Regierungssystem der bayerischen und pfälzischen Wittelsbacher mit stark hilfswissenschaftlichem Schwerpunkt (Urkundenformular, Kanzleiapparat etc.) $)^{2}$ und die auf der prosopographischen Forschung

${ }^{1}$ Z. B. Der deutsche Territorialstaat im 14. Jahrhundert, hrsg. von H. Patze (Vorträge und Forschungen 14/1-2). Sigmaringen 1971; DERs., Die Bildung der landesherrlichen Residenzen im Reich während des 14. Jahrhunderts, in: Stadt und Stadtherr im 14. Jahrhundert. Entwicklungen und Funktionen, hrsg. von W. Rausch (Beiträge zur Geschichte der Städte Mitteleuropas 2). Linz 1972, 1-54; P. Moraw, Personenforschung und deutsches Königtum. Zeitschrift für historische Forschung 2 (1975), 7-18; H. Patze-G. Streich, Die landesherrlichen Residenzen im spätmittelalterlichen Reich. Blätter für deutsche Landesgeschichte 118 (1982), 204-221; E. Müller-Mertens, Die landesherrliche Residenz in Berlin und Köln 1280-1486. Markgrafenhof, Herrschaftsschwerpunkt, Residenzstadt. Zeitschrift für Geschichtswissenschaft 36 (1988), 138-154; D. KERBE, Landesherrliche Residenzburgen im späten Mittelalter, in: Die Burg - ein kulturgeschichtliches Phänomen, hrsg. von H. HofRICHTER (Veröffentlichungen der Deutschen Burgenvereinigung e.V., Reihe B/2). Stuttgart 1994, 60-74; zur Geschichte des Hofes vgl. allgemein den Überblick bei W. Paravicini, Die ritterlich-höfische Kultur des Mittelalters (Enzyklopädie deutscher Geschichte 32). München 1994, 65-71; Р. ЈонаnEK, Höfe und Residenzen, Herrschaft und Repräsentation, in: Mittelalterliche Literatur im Lebenszusammenhang. Ergebnisse des Troisième Cycle Romand 1994, hrsg. von E. C. Lutz (Scrinium Friburgense 8). Freiburg 1997, 45-78.

${ }^{2}$ Vgl. die Aufstellung bei J. Hörmann, Das Registerwesen unter Markgraf Ludwig von Brandenburg in Tirol und Bayern in den Jahren 1342 bis 1352. Phil. Diss. Innsbruck 1998, 31 . 
aufbauenden Untersuchungen der am Hof tätigen Personenverbände von Peter Moraw ${ }^{3}$ und seinen Schülern ${ }^{4}$. Außerdem wurde das Phänomen „Hof" durch die Tätigkeit der von Hans Patze 1985 gegründeten Residenzen-Kommission der Akademie der Wissenschaften zu Göttingen (Arbeitsstelle Kiel) vermehrt in das Blickfeld der wissenschaftlichen Öffentlichkeit gerückt ${ }^{5}$. Vor allem in den letzten Jahren hat speziell der Sonderbereich der so genannten Hofforschung ${ }^{6}$ Beachtung gefunden. In

${ }^{3}$ Vgl. z. B. die einschlägigen Aufsätze in P. Moraw, Über König und Reich. Aufsätze zur deutschen Verfassungsgeschichte des späten Mittelalters, hrsg. von R. Сн. Schwinges aus Anlass des 60. Geburtstages von P. Moraw. Sigmaringen 1995; DERs., Beamtentum und Rat König Ruprechts. Zeitschrift für Geschichte des Oberrheins 116 (1968), 59-126; DERs., Kanzlei und Kanzleipersonal König Ruprechts. AZ 15 (1969), 428-531; DERs., Personenforschung und deutsches Königtum. Zeitschrift für historische Forschung 2 (1975), 7-18.

${ }^{4}$ Hier seien beispielhaft die in P. Monaw (Hrsg.), Deutscher Königshof, Hoftag und Reichstag im späteren Mittelalter (Vorträge und Forschungen 48). Stuttgart 2002, veröffentlichten Kolloquiumsbeiträge zum deutschen Königshof der Jahre 1992/93 genannt, sowie P.-J. Heinig, Kaiser Friedrich III. (1440-1493). Hof, Regierung und Politik (Beiheft zu J. F. Böhmer, Regesta Imperii 17), 3 Bde. Köln-Weimar-Wien 1997, der im Sinne des Forschungsansatzes Peter Moraws den Hof in erster Linie als soziales System unterschiedlicher Personenverbände begreift und deren Wirksamkeit und Mechanismen untersucht. Genannt sei auch noch die für den spätmittelalterlichen österreichischen Raum grundlegende Publikation von C. Lackner, Hof und Herrschaft. Rat, Kanzlei und Regierung der österreichischen Herzoge (1365-1406) (MIÖG Ergbd. 41). Wien-München 2002. Er verbindet und verknüpft die drei aktuellen Modelle - den prosopographischen Ansatz, die Itinerarforschung und die kanzleihistorische Methode -, da nur so „ein annähernd vollständiges Bild vom spätmittelalterlichen Hof" zu gewinnen ist.

5 Über die laufenden Arbeiten, Projekte und Tagungen der Kommission sowie die einschlägige Literatur informieren die regelmäßig erscheinenden Mitteilungen der Residenzenkommission ( $\mathrm{Jg} .1 \mathrm{bis} 14$ ).

${ }^{6}$ Peter Moraw hat in seiner Besprechung des ersten Bandes der Reihe Residenzenforschung den Begriff „Hofforschung“ als die treffendere Bezeichnung für den von Peter Johanek und Werner Paravicini - die Nachfolger Patzes in der Leitung der Residenzen-Kommission - initiierten Schwerpunkt innerhalb der Residenzenforschung angeregt. Damit ließen sich die mit der theoretischen Erfassung und Definition der mittelalterlichen und neuzeitlichen Residenz verbundenen Probleme (vgl. K. Neitmann, Was ist eine Residenz? Methodische Überlegungen zur Erforschung der spätmittelalterlichen Residenzbildung, in: Vorträge und Forschungen zur Residenzfrage, hrsg. von P. JонANEK [Residenzenforschung 1]. Sigmaringen 1990, 11-44; V. Hirsch, Nochmals: Was war eine Residenz im späten Mittelalter? Mitteilungen der Residenzenkommission 13/1 [2003], 12-17) umgehen. Der Hof war ja nicht zwingend an eine feste Residenz gebunden. Die curia gehörte genauso zum reisenden König oder Fürsten. Darüber hinaus benötigt der 
mittlerweile neun Symposien wurden seit 1996 vor allem kulturanthropologische und sozialgeschichtliche Aspekte der europäischen Fürstenhöfe bearbeitet. Die Tagungsbeiträge sind in der seit 1990 geführten Reihe „Residenzenforschung“ erschienen, die zwischenzeitlich auf 15 Bände angewachsen ist ${ }^{7}$; Band 16 und 17 sind in Vorbereitung ${ }^{8}$.

Der Schwerpunkt der „Hofforschung“ liegt überwiegend im Spätmittelalter und in der frühen Neuzeit, was in erster Linie auf die Quellenlage zurückzuführen ist. Tatsächlich sind die Zusammensetzung fürstlicher Höfe, die Aufgabenverteilung und die soziokulturellen Verhältnisse im

auf kulturanthropologische und soziologische Phänomene im Sinne Norbert Elias' konzentrierte Forschungsbereich eine begriffliche Abgrenzung gegenüber den überwiegend verfassungsrechtlichen und politisch-strukturellen Fragen der allgemeinen Residenzenforschung. P. Moraw, Was war eine Residenz im deutschen Spätmittelalter?. Zeitschrift für historische Forschung 18 (1991), 461-468.

7 Residenzenforschung, hrsg. von der Residenzen-Kommission der Akademie der Wissenschaften in Göttingen: Bd. 1: Vorträge und Forschungen zur Residenzenfrage, hrsg. von P. Johanek. Sigmaringen 1990; Bd. 2: K.-U. JÄschke, Nichtkönigliche Residenzen im spätmittelalterlichen England. Sigmaringen 1990; Bd. 3: K. Amann, Die landesherrliche Residenzstadt Passau im spätmittelalterlichen Deutschen Reich. Sigmaringen 1992; Bd. 4: D. Kerber, Herrschaftsmittelpunkte im Erzstift Trier. Hof und Residenz im späten Mittelalter. Sigmaringen 1995; Bd. 5: Alltag bei Hofe, hrsg. von W. Paravicini. Sigmaringen 1995; Bd. 6: Ders., Zeremoniell und Raum. Sigmaringen 1997; Bd. 7: M. Scholz, Residenz, Hof und Verwaltung der Erzbischöfe von Magdeburg in Halle in der ersten Hälfte des 16. Jahrhunderts. Sigmaringen 1998; Bd. 8: J. KolB, Heidelberg - Die Entstehung einer landesherrlichen Residenz im 14. Jahrhundert. Sigmaringen 1999; Bd. 9: M. Mersiowsky, Die Anfänge territorialer Rechnungslegung im deutschen Nordwesten. Spätmittelalterliche Rechnungen, Verwaltungspraxis, Hof und Territorium. Stuttgart 2000; Bd. 10: Höfe und Hofordnungen 1200-1600, hrsg. von H. Kruse-W. Paravicini. Sigmaringen 1999; Bd. 11: J. Hirschbiegel-W. ParaviciNI, Das Frauenzimmer. Die Frau bei Hofe in Spätmittelalter und Früher Neuzeit. Stuttgart 2000; Bd. 12: L. Châtelet-Lange, Die Catharinenburg, Residenz des Pfalzgrafen Johann Casimir von Zweibrücken. Ein Bau der Zeitenwende 16191622. Stuttgart 2000; Bd. 13: Erziehung und Bildung bei Hofe, hrsg. von J. Wettlaufer-W. Paravicini. Stuttgart 2002; Bd. 14: Principes. Dynastien und Höfe im späten Mittelalter, hrsg. von K.-H. Spiess-C. Nolte-G. Werlich. Stuttgart 2002; Bd. 15/1 und 15/2: Höfe und Residenzen im spätmittelalterlichen Reich. Ein dynastisch-topographisches Handbuch, im Auftrag der ResidenzenKommission der Akademie der Wissenschaften, hrsg. von W. PARAvicini. Ostfildern 2003.

${ }^{8}$ Bd. 16: V. Hirsch, Der Hof des Basler Bischofs Johannes von Venningen (14581478). Verwaltung und Kommunikation, Wirtschaftsführung und Konsum. Ostfildern 2004; Bd. 17: Der Fall des Günstlings. Hofparteien in Europa vom 13. bis zum 17. Jahrhundert, hrsg. von W. Paravicini, erscheint Ostfildern 2004. 
Mikrokosmos Hof bis ins 14./15. Jahrhundert hinein nicht mit gewünschter Deutlichkeit und Dichte erfasst. Zwar sind Hofordnungen - die wohl wichtigste Quelle zur Erschließung von Größe und Arbeitsteilung ${ }^{9}$ - in Frankreich, Aragon und England bereits seit dem 13. Jahrhundert erhalten, im deutschsprachigen Raum beginnt aber die Überlieferung im Allgemeinen später ${ }^{10}$. Eine gezielte Auswertung und repräsentative Vergleiche sind daher in größerem Umfang großteils erst ab dem 15. Jahrhundert möglich, auch wenn natürlich, wo es die Quellenlage erlaubt, auch Hofstrukturen des 13. und 14. Jahrhunderts wissenschaftliche Bearbeitung gefunden haben ${ }^{11}$ und Überblicksdarstellungen zur Entstehung königlicher und fürstlicher Höfe bzw. begriffsgeschichtliche Untersuchungen ebenfalls zeitlich weiter zurückreichen ${ }^{12}$. Darüber hinaus ha-

${ }^{9}$ Nach der Definition von Werner Paravicini enthalten Hofordnungen Bestimmungen zur Art der Ämter innerhalb des Hofes, wer sie innehaben soll, mit welchem Gefolge bzw. mit welcher Entlohnung sie zu versehen sind, was zu tun ist und in welcher Form dies zu geschehen hat. In der Praxis werden aber selten alle Punkte in den Ordnungen erfüllt. Vgl. W. Paravicini, Europäische Hofordnungen als Gattung und Quelle, in: Höfe und Hofordnungen (wie in Anm. 7), $13-20$, bes. 14 .

${ }^{10}$ Eine Ausnahme stellen z. B. die 1293/94 in Vilshofen bzw. Regensburg erhaltenen Ordnungen zum Hof der Wittelsbacher Herzöge von (Nieder)Bayern dar. T. Zотz, Hof und Hofordnung vor der Zeit der Verschriftlichung, in: Höfe und Hofordnungen (wie in Anm. 7), 65-73, bes. 71f.

11 Z. B. R. MứlLER, Wiens höfisches und bürgerliches Leben im ausgehenden Mittelalter. Teil 1: Das höfische Leben, vornehmlich im XIV. Jahrhundert, in: Geschichte der Stadt Wien 3, hrsg. von A. Starzer. Wien 1907, 626-686; H. Рatze, Die Hofgesellschaft Kaiser Karls IV. und König Wenzels in Prag. Blätter für deutsche Landesgeschichte 114 (1978), 733-774; F. KavKA, Am Hofe Karls IV. Stuttgart 1990; F. Schwivd, Die Landgrafschaft Thüringen und der landgräfliche Hof zur Zeit der Elisabeth, in: Sankt Elisabeth. Fürstin, Dienerin, Heilige, hrsg. von der Philipps-Universität Marburg. Sigmaringen 1981, 29-44; B. SтReich, Zwischen Reiseherrschaft und Residenzbildung: Der wettinische Hof im späten Mittelalter (Mitteldeutsche Forschungen 101). Köln-Wien 1989. Weiters zur Entstehung landesfürstlicher Höfe und Residenzen aus verwaltungsgeschichtlicher Sicht vgl. im Überblick D. WiLLoweIT, Die Entwicklung und Verwaltung der spätmittelalterlichen Landesherrschaft, in: Deutsche Verwaltungsgeschichte 1: Vom Spätmittelalter bis zum Ende des Reiches, hrsg. von K. G. A. JesErich-H. Pohl-G.-C. von Unruh. Stuttgart 1983, 66-143. Zu den zahlreichen Arbeiten, großteils Dissertationen, die zu den Themen Kanzlei- und Urkundenwesen und Regierungstätigkeit deutscher, vornehmlich bayerischer Fürsten erschienen sind, vgl. Anm. 2.

${ }^{12}$ Z. B. J. Bunke, Höfische Kultur. Literatur und Gesellschaft im hohen Mittelalter. 2 Bde. München ${ }^{2} 1986$; Zotz (wie in Anm. 10), 65-73; vgl. z. B. auch JoHANeK (wie in Anm. 1), 45-78. 
ben die wichtigsten Hofämter und ihre Entwicklungsgeschichte eingehendere Bearbeitungen erfahren ${ }^{13}$.

Für die Grafschaft Tirol, die den politischen Rahmen der vorliegenden Studie bildet, stellt eine spezifische Geschichte der mittelalterlichen landesfürstlichen curia weiterhin ein wissenschaftliches Desideratum dar. Zusammensetzung und Aufgaben der Kanzlei, die Hofämter, namentlich unter Meinhard II. von Tirol-Görz, und Fragen der Regierungs- und Verwaltungsorganisation der Tiroler Landesfürsten haben zwar verschiedentlich Beachtung gefunden ${ }^{14}$, ein entwicklungsgeschichtlicher Überblick steht aber noch aus. Ebenso fehlt eine spezifische Untersuchung des am Hof tätigen „Personals“, das für die Versorgung und den Haushalt der Landesfürsten zuständig war und den inneren Kern der curia bildete $^{15}$. Der Organismus des Hofes mit seinen Zuständigkeiten und Abhän-

${ }^{13}$ Z. B. W. Rösener, Art. Hofämter. LMA 5 (1999), 67f.; Ders., Hofämter an mittelalterlichen Fürstenhöfen. DA 45 (1989), 485-550; P. Schubert, Die Reichshofämter und ihre Inhaber bis um die Wende des 12. Jahrhunderts. MIÖG 34 (1913), 427-501; A. von Wretschko, Das österreichische Marschallamt im Mittelalter. Ein Beitrag zur Geschichte der Verwaltung in den Territorien des deutschen Reiches. Wien 1897; G. Seeliger, Das deutsche Hofmeisteramt im späteren Mittelalter. Eine verwaltungsgeschichtliche Untersuchung. Innsbruck 1885.

${ }^{14}$ F. Huter, Die Anfänge der landesfürstlichen Kanzlei in Tirol. Südostforschungen 14 (1955), 66-84; Nachdr. in: DERs., Ausgewählte Aufsätze zur Geschichte Tirols, hrsg. von M. Cescutti-J. Riedmann (Schlern-Schriften 300). Innsbruck 1997, 138-151. Zu Meinhard II.: R. Heuberger, Das Urkunden- und Kanzleiwesen der Grafen von Tirol, Herzöge von Kärnten aus dem Hause Görz (MIÖG Ergbd. 9). Innsbruck 1915, 50-177, und 265-394; W. KöFler, Studien zum Kanzlei- und Urkundenwesen Meinhards II. (1271-1295). Vorarbeiten zum Tiroler Urkundenbuch. Prüfungsarbeit am Institut für österreichische Geschichtsforschung. Wien 1968; Ders., Beiträge zum Urkundenwesen Meinhards II. in den Jahren 1271 bis 1295. MÖSTA 26 (1973), 56-93; G. PliEger, Die Rechnungsleger in den älteren Tiroler Raitbüchern von 1288-1295. Beiträge zu einer Verwaltungsgeschichte Tirols im ausgehenden 13. Jahrhundert. Phil. Diss. Innsbruck 1990. Zu Heinrich, Titularkönig von Böhmen (und Polen): Heuberger, ebd.; F.-H. Hye-Kerkdal, Geschichte der tirolisch-kärntnerischen Kanzlei unter der Regierung der Herzoge Otto, Ludwig und Heinrich aus dem Hause Görz-Tirol 1295-1310. Vorarbeiten zum Tiroler Urkundenbuch, 1. Hauptteil: Organisation, Wirkungsbereich und persönliche Zusammensetzung der Kanzlei. Prüfungsarbeit am Institut für österreichische Geschichtsforschung. Wien 1965. Zu Ludwig von Brandenburg: H. Schmidbauer, Urkundenwesen, Kanzlei und Regierungssystem unter Markgraf Ludwig dem Brandenburger (1324-1361). Beiträge und Vorarbeiten. Zulassungsarbeit zur wissenschaftlichen Prüfung für das Lehramt an den Gymnasien. München 1970; Hörmann (wie in Anm. 2).

${ }^{15}$ Eingehender bearbeitet ist nur die so genannte Liste der familia domus Tirolis von 1292 (mit Ergänzungen von 1297), die 118 Personen nennt, die auf Burg 
gigkeiten ist für die Zeit vor der schriftlichen Fixierung in Hofordnungen, Lohn- und Ämterlisten naturgemäß schwer zu fassen und eine Rekonstruktion nur über zufällige Erwähnungen in den einschlägigen Quellen (Urkunden, Rechnungsbücher, Register) möglich. Da aber Verschriftlichung und Bürokratisierung der Verwaltung bereits mit Meinhard II. von Tirol-Görz ${ }^{16}$ - unter dessen Regierung der Territorialisierungsprozess in Tirol seinen Abschluss gefunden hat - in ungewöhnlicher Intensität und Vielfalt einsetzen und von seinen Nachfolgern ausgebaut und weiter ,professionalisiert' wurden ${ }^{17}$, ist die Quellenlage, insbesondere für das 14. Jahrhundert, vergleichsweise sehr gut ${ }^{18}$. Der Blick in das mittelalterliche Hofleben scheint daher auf Basis vornehmlich der seit 1288 zahlreich überlieferten Rechnungsbücher, die Ein- und Ausgaben auch der engeren Hofverwaltung verzeichnen, und der Register mit ihren zahlreichen Urkundentexten zumindest in Umrissen möglich. Die Tiroler Hofgesellschaft vor der Verlegung der Residenz von Burg Tirol nach Innsbruck würde sich daher als durchaus lohnendes Forschungsthema für die Zukunft erweisen.

Die diesbezügliche Aussagekraft des zur Verfügung stehenden Quellenmaterials soll im Folgenden am Fallbeispiel des Hofstaates der Landesfürstin Margarethe demonstriert werden, wobei Aufbau und Zusammensetzung der curia im Zentrum stehen. Mit der Existenz eines eigenen

Tirol arbeiteten und für den Haushalt, den Schutz der Burg und Unterhaltung zuständig waren. S. DE Rachewiltz, Die Versorgung von Schloss Tirol, in: Eines Fürsten Traum. Meinhard II. - Das Werden Tirols, Katalog Tiroler Landesausstellung 1995. Schloss Tirol-Stift Stams 1995, 258-265; W. Rösener, Die höfische Frau im Hochmittelalter, in: Curialitas. Studien zu Grundfragen der höfischritterlichen Kultur, hrsg. von J. FLeckenstein (Veröffentlichungen des Max-PlanckInstituts für Geschichte 100). Göttingen 1990, 171-230, bes. 207-209. Ed. bei Heuberger (wie in Anm. 14), 385-387.

${ }^{16}$ H. Wiesflecker, Meinhard II. Tirol, Kärnten und ihre Nachbarländer am Ende des 13. Jahrhunderts (Schlern-Schriften 124). Innsbruck 1955. Nachdr. 1995, 183-243 (Kap. 11: Neubau der Verwaltungseinrichtungen, und Kap. 12: Regierungs- und Verwaltungsführung).

17 Vgl. Lit. in Anm. 14.

18 Ohne auf die Problematik hier näher eingehen zu können, sei angemerkt, dass behördenähnliche Strukturen, die auch unabhängig von der Anwesenheit des Landesfürsten tätig waren und Entscheidungen treffen konnten, in Tirol offenbar bereits zur Mitte des Jhs. ausgebildet waren. Zum Prozess der Entpersonalisierung und quasi Verstaatlichung der Landesherrschaft fehlt freilich noch die grundlegende Forschungsarbeit. Vgl. z. B. Hörmann (wie in Anm. 2), 43-45, und 297-301. 
Hofes für die Landesfürstin verbundene Überlegungen zur Frage weiblicher Selbständigkeit bzw. zur Rolle der Frau als Herrscherin können hingegen nur angerissen werden. Um hier zu verbindlichen Ergebnissen zu kommen, würde es weitergehende Untersuchungen zum selbständigen Itinerar Margarethes und zu ihrer eigenen Urkundenproduktion benötigen, die im Rahmen dieses Beitrages nicht geleistet werden können.

Mit der Thematik betreten wir kein Neuland. Der Aktualität frauenspezifischer Themen entsprechend ${ }^{19}$ fand 1999 ein viel beachtetes Symposium der Residenzen-Kommission mit dem Titel „Das Frauenzimmer. Die Frau bei Hofe in Spätmittelalter und Früher Neuzeit" statt, dessen Beiträge als Band 11 der Reihe „Residenzenforschung“" erschienen sind ${ }^{20}$. Die dort präsentierten Themenstellungen sollen für diese Studie die konzeptuellen Richtlinien bilden.

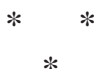

Die curia der Fürstin wird in der Yconomica des Konrad von Megenberg $(1348 / 52)^{21}$ thematisiert. Er beschreibt die bestmögliche personelle Zusammensetzung und den hierarchischen Aufbau eines mittelalterlichen Fürstenhofes $^{22}$. Inwiefern seine allgemeine theoretische Beschreibung

${ }^{19}$ Vgl. das Vorwort des Herausgebers Werner Paravicini im 11. Bd. der Residenzenkommission (wie in Anm. 7), 9-12.

${ }^{20}$ Wie in Anm. 7. Die von Cordula Nolte zusammengestellten Aspekte und Fragestellungen im Kontext von frauenspezifischen und familiären Beziehungen und Rollenverhalten bei Hof und zwischen verwandten Höfen umreißen einen erst in Ansätzen bearbeiteten Themenkomplex innerhalb der Hofforschung. C. Nolte, „Ir seyt ein frembs weib, das solt ir pleiben, dieweil ihr lebt“. Beziehungsgeflechte in fürstlichen Familien des Spätmittelalters, in: Geschlechterdifferenz im interdisziplinären Gespräche, hrsg. von D. RuHE. Würzburg 1998, 11-41.

${ }^{21}$ K. von Megenberg, Werke. Ökonomik, hrsg. von S. KrÜger (MGH Staatsschriften des späteren Mittelalters 3/5, 1-3). Stuttgart 1973-1984; Rösener (wie in Anm. 15), 197-199; G. Drossbach, Die „Yconomica“ des Konrad von Megenberg. Das „Haus" als Norm für politische und soziale Strukturen (Norm und Struktur. Studien zum sozialen Wandel in Mittelalter und früher Neuzeit 6). Köln-Weimar-Wien 1997; DIEs., Sciencia de regimine domus regie: Der Hof zwischen Ideal und Wirklichkeit in der „Yconomica“ Konrads von Megenberg, in: Höfe und Hofordnungen (wie in Anm. 7), 23-35.

${ }^{22}$ Konrad von Megenberg unterscheidet zwischen curiae minores und curiae maiores und meint damit einerseits eine Differenzierung in der Größe der Höfe, wobei kleine Höfe wenige Hofämter, große dagegen - an der Spitze der Königshof einen hohen Spezialisierungsgrad der Ämter aufweisen. Andererseits bezeichnet 
auf die Ämterorganisation am Tiroler Hof in Hinblick auf das weibliche Hofpersonal zutrifft, soll im Folgenden ebenfalls Beachtung finden.

Weibliches Personal und eigener Hofstaat einer Fürstin, zu dem auch Männer gehören konnten, begegnen natürlich nicht erst im späten Mittelalter; bereits seit der zweiten Hälfte des 12. Jahrhunderts lässt sich an manchen Fürstenhöfen ein eigener weiblicher Hofstaat erkennen ${ }^{23}$. Sobald sich die hochmittelalterlichen Landesherrschaften herausbilden und konsolidieren, sind auch im römisch-deutschen Reich neben den männlichen Höfen Hofstrukturen der fürstlichen Gemahlin deutlicher feststell$b^{2}{ }^{24}$. Diese Parallelität erklärt sich auch aus der Reisetätigkeit mittelalterlicher Herrscher ${ }^{25}$ und der damit einhergehenden Trennung von der Ehefrau - sofern sie ihn nicht begleitete ${ }^{26}$. Solange eine feste Residenz fehlte, war der engere Hof beim Fürsten, also ebenfalls mobil und nicht an einem Ort institutionalisiert. Für ihre Hofhaltung und ihre Repräsentation brauchte die Fürstin daher eine eigene, wenn auch zahlenmäßig in der Regel bescheidenere Organisation ${ }^{27}$. An der Spitze der weiblichen

er speziell für die Königshöfe mit curia minor den engeren, für die Versorgung des Hofes zuständigen Haushalt und mit curia maior die Organe der politischen Regierung. Rösener, Höfische Frau (wie in Anm. 15), 197f., und Ders., Hofämter an mittelalterlichen Fürstenhöfen (wie in Anm. 13), 512f.; Drossbach (wie in Anm. 21), 28f. Vgl. auch Јоналек (wie in Anm. 1), 54f.; im Unterschied zur idealen Darstellung bei Konrad von Megenberg enthalten Hofordnungen in der Regel tatsächlich Anordnungen zu Haushalt und Haushaltsführung und nennen Personen, die in einem Dienstverhältnis zu ihren Herren stehen und Lohnempfänger sind. Paravicini (wie in Anm. 9), $17 \mathrm{f}$.

${ }^{23}$ Bumke (wie in Anm. 12), 490.

${ }^{24}$ Eine räumliche Abgrenzung der bei Hofe lebenden und tätigen Frauen ist bereits seit dem 12. Jh. überliefert. Rösener (wie in Anm. 15), 216f. Zu den Erwähnungen und der Bedeutung der Kemenate in der höfischen Literatur des 12. Jhs. P. Strohschneider, Kemenate. Geheimnisse höfischer Frauenräume bei Ulrich von Türlin und Konrad von Würzburg, in: Frauenzimmer (wie in Anm. 7), 29-45, bes. 29-33. Die Bezeichnung „Frauenzimmer“ für den Wohnbereich der Frau, die gleichermaßen auch für den weiblichen Hofstaat verwendet wurde, bürgert sich erst Ende des 15. Jhs. ein und ist erstmals 1470 belegt. Vgl. B. Streich, Frauenhof und Frauenzimmer, in: Frauenzimmer (wie in Anm. 7), 247-262, bes. 248.

${ }^{25}$ Patze (wie in Anm. 1), 1-54. Zur häufigen Trennung der Ehepartner vgl. Streich (wie in Anm. 11), 249-253.

${ }^{26}$ Zum gemeinsamen Itinerar mittelalterlicher Königspaare vgl. A. Fösset, Die Königin im mittelalterlichen Reich. Herrschaftsausübung, Herrschaftsrechte, Handlungsspielräume. Stuttgart 2000, 95-111.

${ }^{27}$ Vgl. z. B. den Haushalt der Königin Maria von Aragon aus dem Jahr 1318: K. SCHWARZ, Aragonesische Hofordnungen im 13. und 14. Jahrhundert. Studien zur Geschichte der Hofämter und Zentralbehörden des Königreichs Aragon. Phil. 
Hofhaltung standen ein Hofmeister und eine Hofmeisterin, die die moralisch-sittliche und organisatorische Verantwortung für die weibliche Dienerschaft trug ${ }^{28}$. Zum Hof der Fürstin gehörten weiters adelige Hofdamen, Jungfrauen ${ }^{29}$, Dienerinnen und Diener sowie sonstiges ,Personal', das durchaus auch männlich besetzt war (Kaplan, Kämmerer, Schreiber, Koch, Schneider, Apotheker ${ }^{30}$, etc. ${ }^{31}$. Nicht alle lebten ständig bei Hof ${ }^{32}$. Die administrative und politische Eigenständigkeit der curia domine wird von Fall zu Fall unterschiedlich zu beurteilen sein. In Abwesenheit des Fürsten waren Aktionsradius und Bedeutung sicher größer; namentlich für die Aufrechterhaltung von Hofversorgung und -verwaltung ${ }^{33} \mathrm{kam}$ der daheim gebliebenen fürstlichen Ehefrau eine entscheidende Rolle zu. Beispiele für politische Einflussnahme bzw. aktive Regierungstätigkeit

Diss. Freiburg i. B. 1913, 117; oder M. Chatenet, Les logis des femmes à la cour des Derniers Valois, in: Frauenzimmer (wie in Anm. 7), 175-192, bes. 176-178; und Rösener (wie in Anm. 15), 210. Die Auswirkungen, die die Bildung einer festen Residenz für die Lebensbedingungen und den Status der Fürstin im Unterschied zur früheren Reiseherrschaft hatten, wurden von Brigitte Streich beispielhaft anhand des wettinischen Hofes untersucht: Streich (wie in Anm. 11), 405-407; DIEs., Frauenhof und Frauenzimmer, in: Frauenzimmer (wie in Anm. 7), 247-262. „Mit dem „Frauenzimmer“ nämlich (Anm. d. Verf.: dem räumlichen Aufenthaltsbereich der weiblichen Gefolgschaft bei Hof; vgl. Anm. 24), das in den wettinischen Quellen zu eben jenem Zeitpunkt in den Quellen auftaucht, als die Reiseherrschaft endet, ändert sich auch für die Frauen das Leben bei Hofe; an die Stelle einer relativen Freiheit und Autonomie trat eine stärkere Beschränkung auf den Raum“ (ebd., 248). Gesonderte Gemächer für die Burgherrin und ihre Dienerschaft waren aber bereits im 12. Jh. nichts Ungewöhnliches. Vgl. Rösener (wie in Anm. 15), $216 \mathrm{f}$.

${ }^{28}$ Megenberg (wie in Anm. 21), I, 258-260; Drossbach (wie in Anm. 21), 114; Múller (wie in Anm. 11), 656f.; A. Kircher-Kannemann, Organisation der Frauenzimmer im Vergleich zu männlichen Höfen, in: Frauenzimmer (wie in Anm. 7), 235-240, bes. 242-245; Streich (wie in Anm. 11), 407; etwas abweichend davon Seetiger (wie in Anm. 13), 46f.; weiters Lackner (wie in Anm. 4), 51-53.

${ }^{29}$ Zum Begriff „Jungfrau“ vgl. Rösener (wie in Anm. 15), 198, Anm. 114.

30 W. Paravicini, Das Frauenzimmer. Die Frau bei Hofe in Spätmittelalter und Früher Neuzeit, in: Frauenzimmer (wie in Anm. 7), 20, Anm. 52.

${ }_{31}$ M. A. BoJcov, „Das Frauenzimmer“ oder „Die Frau bei Hofe“?, in: Frauenzimmer (wie in Anm. 7), 327-338, bes. 328f.

${ }^{32} \mathrm{Vgl}$. Patze (wie in Anm. 11), 753-755.

${ }^{33}$ Vgl. z. B. die Aufgaben der hl. Elisabeth als Landgräfin von Thüringen: Rösener (wie in Anm. 15), 199-206; Schwind (wie in Anm. 11), 41; E. Goez, Beatrix von Hohenstaufen. Eine politische Kaiserin?, in: Frauen bei Hof, hrsg. von O. Borst (Stuttgarter Symposien. Schriftenreihe 6). Tübingen 1998, 28-40; A. SсHWEICKERT, Mechthild von der Pfalz. Eine Frau der Tat im 15. Jahrhundert, in: ebd., 41-56; allg. Rösener, ebd., 227f. 
von Herrscherinnen sind nicht selten ${ }^{34}$. Andererseits ist für das Spätmittelalter im Allgemeinen ein Rückgang weiblicher Mitregentschaft zu beobachten, der nicht zuletzt in Zusammenhang mit der Entpersonalisierung des Staatsgedankens, d. h. der Ausbildung von Regierungsbehörden im Sinne moderner Staatlichkeit zu sehen ist ${ }^{35}$.

Inwiefern lassen sich nun aber diese allgemeinen Feststellungen auch für die Tiroler Verhältnisse im 14. Jahrhundert bestätigen? Generell lässt sich festhalten, dass die Ausbildung der Landesherrschaft, die Ende des 13. Jahrhunderts unter Meinhard II. von Tirol-Görz weitgehend abgeschlossen war, zwar später als in anderen Territorien des römisch-deutschen Reiches stattgefunden, deren administrativer Standard aber schon sehr früh ein vergleichsweise beachtliches Niveau erreicht hat ${ }^{36}$. Burg Tirol oberhalb von Meran bildete als Sitz der Grafen von Tirol und späteren Landesfürsten das Herrschaftszentrum ${ }^{37}$. Doch waren auch Meinhard II. und seine Nachfolger ,reisende‘ Fürsten, die mit ihrem Hof und ihren Ratgebern die landesfürstlichen Stützpunkte aufsuchten. Das Itinerar Meinhards II. zeigt diese Mobilität deutlich ${ }^{38}$. Als Margarethe ,Maultasch“, Enkelin Meinhards II. und Erbin des Landes Tirol, sich in zweiter Ehe mit Ludwig von Brandenburg, dem ältesten Sohn Kaiser Ludwigs des Bayern, verheiratete, nahm diese Reisetätigkeit gravierend zu, denn Ludwig war zeitweise gleichzeitig Tiroler Landesfürst, Herzog von Bayern und Markgraf von Brandenburg ${ }^{39}$ und hatte überall seine

34 Bumke (wie in Anm. 12), 484-490; Rösener (wie in Anm. 15), 227f.; Streich (wie in Anm. 24), 258-260; R. Hiestand, Eirene basileus - Die Frau als Herrscherin im Mittelalter, in: Der Herrscher. Leitbild und Abbild in Mittelalter und Renaissance, hrsg. von H. HEckER (Studia humaniora 13). Düsseldorf 1990, 253-284, bes. 260-263; K-U. JÄschкE, Notwendige Gefährtinnen. Königinnen der Salierzeit als Herrscherinnen und Ehefrauen im römisch-deutschen Reich des 11. und beginnenden 12. Jahrhunderts (Historie und Politik 1). Saarbrücken 1991.

35 Streich, ebd., 262.

36 S. oben S. 82.

37 Die Residenzfunktion hat noch keine eingehendere wissenschaftliche Analyse erfahren. Zu den Argumenten, die für die zentrale Rolle von Burg Tirol sprechen, vgl. Hörmann (wie in Anm. 2), 34f., Anm. 163; wichtige Aufschlüsse zur Bedeutung der Anlage bietet auch die Baugeschichte; dazu bzw. zu Schloss Tirol allg. J. Hörmann, Schloss Tirol. Lana 2004 (mit der älteren Literatur).

38 M. Staudinger, Das Itinerar Meinhards II. von Tirol, Graf von Tirol-Görz und Herzog von Kärnten 1259-1295. Phil. Diplomarbeit. Innsbruck 1996.

39 Mit dem Titel eines Herzogs von Kärnten war keine reale Machtausübung verbunden. Nach dem Tode seines Schwiegervaters Heinrich, Titularkönigs von Böhmen, war Kärnten, das die Grafen von Tirol-Görz seit 1286 zu Lehen hatten, an die Habsburger Herzöge verloren gegangen. Sowohl Ludwig wie auch Margarethe hielten aber den Anspruch auf das Herzogtum stets in ihrem Titel aufrecht. 
Regierungsaufgaben wahrzunehmen, zumal die politischen Verhältnisse vor allem in Tirol und Brandenburg zunächst keineswegs zu seinen Gunsten standen und seine Anwesenheit da wie dort erforderten ${ }^{40}$. Dies zwang ihn zu einer gesteigerten Mobilität, die wiederum als Konsequenz einen auch selbständig tätig werdenden ,Beamtenapparat nötig machte ${ }^{41}$. Burg Tirol blieb auch unter seiner Regierung bevorzugter Sitz von Verwaltung, Kanzlei ${ }^{42}$ und landesfürstlichem Hof ${ }^{43}$, wobei ein Teil des Hofes - Diener, Schreiber, diverse Amtsträger - den Markgrafen auf seinen Reisen natürlich stets begleitete.

Margarethe mit ihrer kranken Schwester, ihren Kindern ${ }^{44}$ und ihrem Hofstaat lebte in erster Linie auf Burg Tirol. Ihr Schicksal als Fürstengattin war einerseits typisch für Frauen in ihrer Position, wies andererseits aber auch spezifische Unterschiede auf. So war sie zwar früh zum Ziel heiratspolitischer Interessen geworden, wurde jedoch nicht, wie viele ihrer Standesgenossinnen, an einen fremden Hof verheiratet ${ }^{45}$. Als Alleinerbin der Grafschaft Tirol kam der Ehemann zu ihr und nicht um-

${ }^{40}$ Zum Itinerar Ludwigs bis 1351 (in diesem Jahr bekommt Brandenburg sein jüngerer Bruder Ludwig der Römer) vgl. die Aufstellung bei W. H. Bıєr, Märkische Siegel. 1. Abt.: Die Siegel der Markgrafen und Kurfürsten von Brandenburg. Teil 2: Die Siegel der Markgrafen von Brandenburg aus dem Hause Wittelsbach 1323-1373 (Veröffentlichungen der Historischen Kommission für die Provinz Brandenburg und die Reichshauptstadt Berlin 6). Berlin 1933. Zur Situation in Tirol und Brandenburg zusammenfassend Hörmann (wie in Anm. 2), 7-22.

${ }^{41}$ Z. B. wurde Ende der 1340er Jahre eine eigene tirolische Kanzlei in Burg Tirol eingerichtet, die auch in Abwesenheit des Landesfürsten Urkunden ausstellen und besiegeln konnte. So genannte commissores, das waren in der Regel der Landeshauptmann oder Mitglieder des landesfürstlichen Rates, übernahmen in Vertretung des Landesfürsten die Verantwortung für den Inhalt. Zur Entwicklung der Kanzlei unter Ludwig von Brandenburg bzw. zur Entwicklung behördenähnlicher Strukturen vgl. Hörmann (wie in Anm. 2), 43-45, 290f., 297301.

${ }^{42}$ Zentrum der bereits unter Meinhard II. aufgebauten Verwaltungsorganisation mit untergeordneten dezentralen Landgerichten, Urbarämtern, Zollämtern und der Saline in Hall waren die Kanzlei und Kammer, deren Agenden vielfach ineinander übergingen. Hörmann (wie in Anm. 2), 35.

${ }^{43}$ D. h. der curia minor im Sinne Konrads von Megenberg; vgl. Anm. 22.

${ }^{44}$ J. Hörmann, Herzog Meinhard III. und seine Geschwister. Überlegungen zur Nachkommenschaft Markgraf Ludwigs von Brandenburg und der Margarethe ,Maultasch'. Zeitschrift für bayerische Landesgeschichte 64 (2001), 309-336.

${ }^{45}$ K.-H. Spiess, Unterwegs zu einem fremden Ehemann. Brautfahrt und Ehe in europäischen Fürstenhäusern des Spätmittelalters, in: Fremdheit und Reisen im Mittelalter, hrsg. von I. ERFen - K.-H. Spieß. Stuttgart 1997, 17-36; Nolte (wie in Anm. 20), 11-41. 
gekehrt $^{46}$. Ihre erste Ehe mit dem Sohn des Königs von Böhmen, mit dem sie jung verheiratet worden und gemeinsam auf St. Zenoburg ${ }^{47}$ und Burg Tirol aufgewachsen war, scheiterte schon nach wenigen Jahren. Ihre Trennung im Jahre 1341 erregte internationales Aufsehen und zerstörte die luxemburgischen Pläne, nach dem Besitz des strategisch wichtigen Passlandes Tirol zu greifen ${ }^{48}$. Ihr zweiter Mann wurde der Sohn des Kaisers, der Wittelsbacher Ludwig von Brandenburg, der seit Anfang 1342

${ }^{46}$ Vergleichbar ist diese Situation etwa mit der Nachfolgeregelung nach dem Aussterben der Přemysliden in Böhmen, die auch jeweils über die angeheirateten Ehemänner erfolgte. So wurde der Tiroler Landesfürst Heinrich über seine erste Gattin Anna von Böhmen, Schwester des 1306 verstorbenen Königs Wenzel III., König von Böhmen, und Johann von Luxemburg legitimierte seine Wahl zum König von Böhmen über deren jüngere Schwester Elisabeth von Böhmen; vgl. F. SEIBT, Karl IV. Ein Kaiser in Europa, 1346 bis 1378. München 1994, 76-78. Ein weiteres Beispiel ist die Eheschließung Sigismunds von Luxemburg mit der ungarischen Erbtochter Maria. Auch in diesem Fall kam der Bräutigam zur Braut; vgl. J. K. Hoznsch, Kaiser Sigismund. Darmstadt 1996, 45-63. Zur weiblichen Erbfolge: K.-H. SpIEss, Familie und Verwandtschaft im deutschen Hochadel des Spätmittelalters. 13. bis Anfang 16. Jahrhundert (Vierteljahrschrift für Sozialund Wirtschaftsgeschichte, Beihefte 111). Stuttgart 1993, 337-343; weitere Beispiele bei Hiestand (wie in Anm. 34), 261-263.

47 Ein Brand dürfte Anfang des 14. Jhs. Teile der Burg Tirol zerstört haben. Ihr Vater Heinrich verlegte daher zeitweilig seinen Sitz in die nahe gelegene Burg St. Zenoberg, wo auch Margarethe einen Teil ihrer Jugend verbrachte.

48 Der Trennungsskandal hat mehrfach - auch außerhalb Tirols - das Interesse der Wissenschaft geweckt. Vgl. z. B. H. Nehlsen, Die Rolle Ludwigs des Bayern und seiner Berater Marsilius von Padua und Wilhelm von Ockham im Tiroler Ehekonflikt, in: Kaiser Ludwig der Bayer. Konflikte, Weichenstellungen und Wahrnehmung seiner Herrschaft, hrsg. von H. Nehlsen und H.-G. Hermann (Quellen und Forschungen aus dem Gebiet der Geschichte N. F. 22). Paderborn-MünchenWien-Zürich 2002, 283-328; U. Wegner, Die Eheangelegenheit der Margarethe von Tirol: Überlegungen zur politischen und kulturhistorischen Bedeutung des Tiroler Eheskandals (Akademische Abhandlungen zur Geschichte). Berlin 1996; J. Riedmann, Karl IV. und die Bemühungen der Luxemburger um Tirol. Blätter für deutsche Landesgeschichte 114 (1978), 775-796; W. BAum, Margarete Maultasch. Erbin zwischen den Mächten. Graz-Wien-Köln 1994, 80-94; weiters DERs., Tirol und Böhmen im Zeitalter König Johanns von Böhmen (1310-1346). Der Schlern 70 (1996), 678-686; zur Reaktion in der zeitgenössischen Historiographie DERs., Margarethe Maultasch in Geschichte und Sage. Zur Kritik historischer Mythen und der Tradierung von Vorurteilen. Carinthia I 183 (1993), 367-408. Zur Heiratspolitik König Johanns von Böhmen vgl. D. Veldtrup, Ehen aus Staatsräson. Die Familien- und Heiratspolitik Johanns von Böhmen, in: Johann der Blinde, Graf von Luxemburg, König von Böhmen (1296-1346), hrsg. von M. Pauly. Luxemburg 1997, 483-543, bes. 516-535. 
auf Burg Tirol residierte und als ,angeheirateter' Landesfürst die Regierung übernahm ${ }^{49}$.

Die engere Hofverwaltung und -versorgung auf der wichtigsten Residenzburg des Landes war spätestens seit den Tagen Meinhards II. ein gut funktionierender Organismus. Und so sind auch die Erwähnungen von persönlichen Dienern Ludwigs - Köchen, Handwerkern, Schreibern, Musikern, Ärzten etc. - überaus zahlreich in den Registern und Rechnungsbüchern zu finden. Margarethe führte parallel zum Hofstaat Ludwigs einen eigenen Haushalt mit eigenem Personal und wohl auch eigener Hierarchie $^{50}$. Dieser im Folgenden in seiner Zusammensetzung näher vorgestellte weibliche Hof gründet sich einerseits in der häufigen Abwesenheit des Ehemannes, andererseits sind aber bereits für Margarethes Vorgängerinnen eigenständige Hofstrukturen bezeugt. Die Frauen der Tiroler Landesfürsten hatten offenbar schon früh eine relative Selbständigkeit erreicht, die auch außerhalb des Hofes wirksam wurde. Namentlich Beatrix von Savoyen, die dritte Frau König Heinrichs, und dessen Schwägerin Eufemia von Breslau, Witwe des 1310 verstorbenen Herzogs Otto von Kärnten(-Tirol), sind diesbezüglich eingehender untersucht ${ }^{51}$. Sie hatten beide eigene Schreiber, eigenes Personal, eigene Hofstrukturen ${ }^{52}$ und auch

49 Die Frage nach politischer Aktivität und Einflussnahme Margarethes ist nicht Thema dieser Studie, daher sei hier nur die Beobachtung vermerkt, dass bis auf die ,Vertreibung“ des ungeliebten Johann von Böhmen und die Verteidigung von Burg Tirol 1347 bis zum Tod Ludwigs 1361 keine weit reichenden politischen Handlungen der Landesfürstin zu erkennen sind. Vgl. auch S. 123f. Zu Ludwig von Brandenburg immer noch grundlegend F. H. Haug, Ludwigs V. des Brandenburgers Regierung in Tirol (1342-1361). Forschungen und Mitteilungen zur Geschichte Tirols und Vorarlbergs 3 (1906), 257-308, und 4 (1907), 1-53; weiters H. Schmidbauer, Herzog Ludwig V. von Bayern (1315-1361). Anmerkungen zu seiner Biographie. Zeitschrift für bayerische Landesgeschichte 55 (1992), 77-87.

${ }^{50}$ Die Rekonstruktion wird dadurch erleichtert, dass man auch in den Kanzleibüchern und Urkunden - wenn auch sicher nicht konsequent - zwischen Dienern des Herzogs und der Herzogin zu unterscheiden versuchte. So steht etwa domicella domine, famulus domine etc., um die Zugehörigkeit zum Hofgesinde der Landesfürstin auszudrücken.

51 A. Aliuevich, Documenti su Beatrice di Savoia contessa di Tiralli. Archivio per l'Alto Adige 27 (1932), 249-315; J. Riedmann, Die Beziehungen der Grafen und Landesfürsten von Tirol zu Italien bis zum Jahre 1335 (SB ÖAW, phil.-hist. Klasse 307). Wien 1977, 447-452; J. Ladurner, Euphemia, Herzogin von Kärnthen, Gräfin von Tirol. Archiv für Geschichte und Alterthumskunde Tirols 1 (1864), 107-139.

${ }^{52}$ Heuberger (wie in Anm. 14), 165f. Auch für König Heinrichs erste Frau, Anna von Böhmen, sind in den Rechnungsbüchern einige ,Beamte“ ihres Hofstaates belegt. Vgl. L. SсHÖNACH, Beiträge zur Geschichte der Königin Anna von Böhmen 
eigenes Vermögen, über das sie verfügen konnten. Insbesondere Beatrix lieh wiederholt ihrem stets geldbedürftigen Mann auch höhere Geldsummen $^{53}$.

Was den Ehefrauen von Vater und Onkel möglich war, musste wohl auch für die Erbin des Landes Geltung haben. Vorderhand sei daher das Umfeld Margarethes im engeren Kreis des Hofes näher beleuchtet, wobei in erster Linie der Frage nachgegangen werden soll, welche Ämter es innerhalb des Hofstaates der Landesfürstin gegeben hat, wer sie nach Ausweis der Quellen innehatte und wie sich die Organisation und die Aufgabenverteilung gestalteten, sofern dies aufgrund der Quellenlage festzustellen möglich ist.

\section{Hofmeisterin und Hofmeister}

Dem üblichen, auch bei Konrad von Megenberg so dargestellten Schema folgend standen an der Spitze der Hierarchie eine Hofmeisterin und ein Frauenhofmeister, der nicht mit dem Hofmeister Ludwigs bzw. des Gesamthofes identisch war ${ }^{54}$. Bezüglich der Inhaber der beiden Ämter sind nur zwei Namen in den Quellen etwas präsenter. Als Hofmeisterin ist überhaupt nur Beatrix die Moretscherin genannt und auch Gebhard Hornbeck blieb als Hofmeister Margarethes über mehrere Jahre im Amt und ist vergleichsweise häufig in dieser Funktion erwähnt.

Insbesondere für Beatrix war der Hof ihr Lebensumfeld, stand sie doch schon in Diensten von Margarethes Stiefmutter Beatrix von Savoyen und war mit ihr ins Land gekommen. Durch ihre Heirat mit Dietrich Moretscher blieb sie auch nach dem Tod ihrer Herrin in Tirol und war weiterhin in landesfürstlichen Diensten tätig. Ihr ehelicher Stand war ihrer Stellung bei Hof offenbar nicht hinderlich ${ }^{55}$. Als Hofmeisterin begegnet

$(†$ 1313). Mitteilungen des Vereines für Geschichte der Deutschen in Böhmen 45 (1907), 121-133, bes. 123 .

53 Riedmann (wie in Anm. 51), 450.

${ }^{54} \mathrm{Zu}$ den Hofmeistern Ludwigs vgl. die Biographien zu den landesfürstlichen Amtsträgern bei Schmidbauer (wie in Anm. 14), 113-145.

${ }_{55}$ Beatrix von Savoyen hat die Heirat ihrer Jungfrau mit einer Mitgift von 300 Mark unterstützt und übergab dem Paar 1331 überdies noch die Burghut von Montani. Auch in ihrem Testament wurde die Moretscherin berücksichtigt. RIEDManN (wie in Anm. 51), 448 (mit weiteren Urkundennennungen), und Aliuevich (wie in Anm. 51), 287f., Nr. 21, 309, Nr. 46, und 312f., Nr. 51 und 52. Beatrix blieb auch nach ihrer Verheiratung in landesfürstlichen Diensten, was an sich nicht üblich war; vgl. LackNer (wie in Anm. 4), 52. 
sie in den Quellen erstmals in einer Raitung des Haller Salzmeiers Schine von Florenz für die Jahre 1342 und $1343^{56}$; die letzte Eintragung datiert Ende $1347^{57}$. Insgesamt liegen zehn Nennungen der Hofmeisterin vor ${ }^{58}$ : Neben Geldzuweisungen und Geschenken verleiht ihr Ludwig von Brandenburg im November 1344 als Dank für ihre treuen Dienste den Rasphof in Latsch, den sie vorher als Pfand innehatte ${ }^{59}$. Dass der neue Landesfürst auch dem Ehemann Dietrich Moretscher sein Wohlwollen entgegenbrachte, zeigt weiters u. a. die Bestätigung eines Teils der Burg Montani, die ihm bereits früher Herzogin Margarethe verliehen hatte ${ }^{60}$. Montani, im mittleren Vinschgau am Eingang des Martelltales gelegen, war nicht der ideale Wohnort für einen Arbeitsplatz auf Burg Tirol. So dürfte wohl das Ehepaar großteils getrennt gelebt haben. Während Beatrix in Burg Tirol ihren Dienst versah und wahrscheinlich dort auch wohnte bzw. Margarethe auf ihren Reisen begleitete, hatte Dietrich seine Pflichten als Pfleger von Montani wahrzunehmen. Wie seine Frau findet er nur bis 1347 Erwähnung in den Quellen ${ }^{61}$. Ob beide verstorben sind oder andere Gründe dafür ausschlaggebend waren, lässt sich nicht mehr sagen ${ }^{62}$. Von einer

56 Innsbruck, Tiroler Landesarchiv (künftig TLA), Cod. 288, fol. $10^{\mathrm{r}}$.

57 TLA, Cod. 129, Nr. 339 (Notiz; 1347 Dezember 7, Tirol): Schenkung eines Pferdes an die Hofmeisterin.

58 Darunter einige Parallelüberlieferungen.

591344 November 9, Meran; Orig. München, Bayerisches Hauptstaatsarchiv (künftig BHStA), Urk. Grafschaft Tirol, Nr. 81; Abschriften: TLA, Cod. 20, fol. 41 ${ }^{\mathrm{rv}}$, und Wien, Haus-, Hof- und Staatsarchiv (künftig HHStA), Cod. R. 55, Nr. $98^{\mathrm{r}} / 5$ (Notiz); vgl. Innsbrucker Schatzarchiv-Urkunden in München von 1222 bis 1400 (1451), bearb. von S. HölzL-P. Moser (Tiroler Geschichtsquellen 10). Innsbruck 1981, Nr. 81. Der Hof in Latsch war 1343 März 20 von Ludwig an das Paar gemeinsam verpachtet worden; vgl. HHStA, Cod. R. 55, Nr. 59 und fol. $98^{\mathrm{r}} / 3$ (Notiz); weitere Parallelüberlieferung in TLA, Cod. 20, fol. 40\% 1.

60 Die Burghut hatten Dietmar und Beatrix bereits von Herzogin Beatrix übertragen bekommen; vgl. Anm. 55; 1344 April 17; - 20, fol. 40/1: .. daz purckgesaezze gelegen in unsrer veste ze Munteny hineinwerts ze der rechten seiten pei dem tór... in aller der weyse als der brief beweyset, den in unser liebeu gemahel vor daruber geben hat ..., und HHStA, Cod. R. 55, fol. 98 $/ 1$ (Notiz); Orig. im TLA, Urk. I 8940 [Ed. K. Spert, Margarethe von Tirol, genannt Maultasch. Eine biographische Skizze. Phil. Diplomarbeit Wien 2002, Nr. 18; M. KIEM, Briefe und Urkunden, vornehmlich aus Südtirol. Zeitschrift des Ferdinandeums für Tirol und Vorarlberg 37 (1893), 364-377, bes. 366f.]; R. STAFFLER, Die Hofnamen im Landgericht Schlanders (Schlern-Schriften 13). Innsbruck 1927, $66 \mathrm{f}$.

${ }^{61}$ TLA, Cod. 62, fol. 202 ${ }^{\text {r }}$ (Raitung von 1347 März 4). Die Erwähnungen betreffen in erster Linie Zahlungen in Zusammenhang mit der Burghut von Montani.

${ }^{62}$ Burg Montani u. a. Lehen werden jedenfalls erst 1357 an Matthias, einen natürlichen Bruder Margarethes, wieder neu verliehen. TLA, Cod. 159, fol. $114^{\mathrm{r}}$ (1357 September 29, Sterzing), und fol. $66^{\mathrm{v}}$ (1357 November 10, Tirol). 
Nachfolgerin der Moretscherin ist ebenfalls nichts bekannt. Wurde mit ihrem Ausscheiden das Amt der Hofmeisterin abgeschafft? Kinder hat das Paar nach Ausweis der Quellen keine gehabt.

Über den Aufgabenbereich der Hofmeisterin erfahren wir nichts. Über den engeren Haushalt hinaus, in dem sie die Verantwortung für das ,Personal` und die organisatorischen Abläufe gehabt haben dürfte und Repräsentationspflichten als Begleiterin der Fürstin wahrzunehmen hatte $e^{63}$, oblagen ihr offenbar keine Agenden. Weder taucht sie als Zeugin in den Rechnungslegungen der Raitbücher auf ${ }^{64}$, noch in den commissorVermerken der Registereintragungen ${ }^{65}$, noch finden wir sie an einem der zahlreichen administrativen Vorgänge beteiligt.

Wesentlich aktiver war diesbezüglich der männliche Hofmeister der Herzogin, Gebhard Hornbeck. Wie Beatrix war auch er kein Einheimischer. Er kam mit Ludwig von Brandenburg nach Tirol und wurde wahrscheinlich von ihm auch als Hofmeister für seine Frau und ihren Hof bestimmt. Seine Vorgänger in dieser Funktion waren Heinrich Rasp und Heinrich Graf von Eschenloch ${ }^{66}$. Rasp war ein enger Vertrauter Heinrichs von Böhmen und während der Jugendjahre der Herzogin bzw. in der Zeit ihrer ersten Ehe Frauenhofmeister und 1340 führend bei dem ersten Aufstand gegen die Böhmenherrschaft in Tirol beteiligt. Das Scheitern dieser Erhebung brachte Heinrich Rasp Gefangenschaft, Verlust seiner Matreier Burg (Raspenbühel) und kostete ihn wohl auch seine Hofmeisterwürde. Während der Regierung Ludwigs von Brandenburg

${ }^{63}$ Zumindest gehörte dies andernorts zu den Aufgaben der Hofmeisterin. Vgl. die Frauenhofordnungen des 16. Jhs. Kircher-Kannenmann (wie in Anm. 28), $239 f$.

${ }^{64}$ Zeugenschaft war eine Domäne der Männer.

${ }_{65}$ In den so genannten commissor-Vermerken wird von der Kanzlei festgehalten, wer anstelle des Landesfürsten in dessen Namen die Urkunden ausstellte. Meist fiel dies in die Kompetenz des landesfürstlichen Rates, fallweise werden aber auch Personen von außerhalb genannt. Zum Problem der Stellvertreter-Urkunden vgl. Hörmann (wie in Anm. 2), 286-296.

${ }_{66}$ TLA, Cod. 288, fol. 14 (Raitung des Konrad von Schenna für die Jahre 1343/44): Primo exsolvit apud Steynam dictam Faelschlin de Inspr(uck) clainodia argentea tempore quo dominus H(einricus) comes de Escheloch fuit magister curie domine pro V(er)on(ensium) marcas XII. 1342 September 29 weist Herzogin Margarethe Berchtold, Richter in Passeier, an, dem Grafen Heinrich von Eschenloch Ausgaben von siebeneinhalb Pfund Berner (= Veroneser), die dieser für sie, den Markgrafen und ihr Gefolge ausgelegt hat, zurückzuerstatten. Eschenloch wird hier zwar nicht direkt als Hofmeister angesprochen, der Zusammenhang lässt aber darauf schließen. TLA, Urk. I 9560 a/2 [Ed. Sperl (wie in Anm. 60), Nr. 12]. 
spielte er keine Rolle mehr. Auf eine vorübergehende Ungnade des ehemaligen Frauenhofmeisters lässt die 1354 beurkundete Wiederverleihung der Güter schließen, die Heinrich Rasp bereits früher von Ludwig und Margarethe innehatte ${ }^{67}$. Als sein Nachfolger im Amt des Hofmeisters der curia domine wurde Heinrich Graf von Eschenloch eingesetzt, der allerdings spätestens im Frühjahr 1343 sein Amt hatte abgeben müssen, da Gebhard von Hornbeck in einer Raitung vom April 1343 in der Zeugenliste bereits als Hofmeister der Herzogin erwähnt ist ${ }^{68}$. Heinrich von Eschenloch war ein unehelicher Sohn König Heinrichs und somit ein Bruder Margarethes ${ }^{69}$. Vielleicht bedeutete diese verwandtschaftliche Beziehung ein zu enges Nahverhältnis; für den landfremden Ludwig war einer seiner Vertrauensleute in dieser Position sicher angenehmer. Dass Gebhard tatsächlich zum engeren ,Mitarbeiterstab ' des Landesfürsten zu zählen ist, zeigt seine Zugehörigkeit zum landesfürstlichen Rat ${ }^{70}$, dem

${ }^{67}$ Haug (wie in Anm. 49), Bd. 3, 264, Anm. 1, 267 mit Anm. 3, und 268 mit Anm. 1. HHStA, Cod. W. 209, Nr. 90 (1354 Dezember 5, Innsbruck; mit Parallelüberlieferung im TLA, Cod. 109, fol. 100 ); L. Steinberger, Die zwei Burgen von Matrei im Wipptale, in: Tirolensia. Zum 80. Geburtstag Konrad Fischnalers (Schlern-Schriften 30). Innsbruck 1935, 176-193, bes. $179 \mathrm{f}$.

${ }^{68}$ TLA, Cod. 62, fol. 171 ${ }^{\mathrm{r}}$ (1343 April 11): Raitung des Jäklin von Ulten, genannt Judlin von Meran, über alle Einkünfte, die er aus den Gütern des Volkmar von Burgstall im Jahr 1342 bekommen hat. Unter den Zeugen ist Gebhard Hornbeck als Hofmeister der Herzogin Margarethe genannt. Desgleichen ebd., fol. 172 in der Raitung des Grafen Heinrich von Eschenloch von 1343 April 24 für ein Jahr (1342/43). In Raitungen zu 1342/43 im Cod. Nr. 288 ist er ebenfalls erwähnt, jedoch ohne Funktionsbezeichnung; vgl. TLA, Cod. 288, fol. 9 (Raitung des Haller Salzmeiers Schine von Florenz). Und auch in der ersten urkundlichen Erwähnung Hornbecks von 1343 März 14, Meran, wird er nicht als Hofmeister geführt. HHStA, Cod. R. 55, fol. $68^{\text {rv }}$. Vgl. dazu auch Schmidbauer (wie in Anm. 14), 130; Schmidbauer datiert allerdings die erste Erwähnung erst 1346. Weiters in der Urkunde TLA, Urk. I 8940 (1344 April 17, ohne Ortsangabe) unter den Zeugen erwähnt (Gebhart der Hoerenbeck unserer lieben gemaheln hofmeister); vgl. Anm. 60.

${ }^{69}$ Wurde in Heinrich von Eschenloch, der erstmals 1308 in den Quellen erscheint, zunächst ein natürlicher Sohn Meinhards II. vermutet, dürfte es sich tatsächlich um einen illegitimen Sohn des Landesfürsten Heinrich handeln, da dieser in einer Raitung explizit als Vater bezeichnet wird. Vgl. O. Trapp, Eschenloch (Ulten), in: Tiroler Burgenbuch 2: Burggrafenamt. Innsbruck-Wien-Bozen 1973, 251257, bes. 252f. mit Anm. 13.

${ }^{70}$ Z. B. HHStA, Cod. R. 55, Nr. 143 (1346 Februar 6, Tirol) und Parallelüberlieferung im HHStA, Cod. Bl. 127, Nr. 85: Pfandverschreibung für Konrad von Schenna. Bei der vorangegangenen Rechnungslegung waren neben Ludwig und Margarethe auch Mitglieder des landesfürstlichen Rates anwesend, darunter Gebhard von Hornbeck; weiters BHStA, Grafschaft Tirol, Nr. 85 (Abschrift im 
obersten Gremium der Regierung. Häufig erscheint er in den commissorVermerken $^{71}$, und auch in Raitungen und Pfandverschreibungen ist er mehrfach als Zeuge erwähnt ${ }^{72}$. Darüber hinaus fungierte er als Schiedsrichter $^{73}$ und beglaubigte mit seinem Siegel landesfürstliche Urkunden ${ }^{74}$. Vor allem letzteres stellt auch für Mitglieder des Rates eine Besonderheit dar und zeugt von der Vertrauensstellung, die Gebhard von Hornbeck bei Ludwig genoss. Als besondere Auszeichnung ist weiters die Bestellung in das Beratergremium Hilpolds von Stain zu werten ${ }^{75}$, der während der Jahre, in denen Herzog Albrecht II. von Österreich von Ludwig die Herrschaft in Oberbayern übertragen bekommen hatte, als Hauptmann in Oberbayern eine Art Stellvertreterregierung für Albrecht führte ${ }^{76}$. Als

HHStA, Cod. R. 55, Nr. 148 und Parallelüberlieferung im HHStA, Cod. Bl. 127, Nr. 84, 1346 Februar 12, Tirol): Bei der Abrechnung mit den Erben und Vormündern des Tegen von Vilanders war unter den genannten landesfürstlichen Räten auch Gebhard Hornbeck anwesend; vgl. HöLzL-Moser (wie in Anm. 59), Nr. 85. Die Beteiligung des Frauenhofmeisters an Regierungsgeschäften und seine Zugehörigkeit zum landesfürstlichen Rat sind auch anderweitig zu belegen; vgl. Streich (wie in Anm. 11), 15lf; Dies. (wie in Anm. 24), 260; Lackner (wie in Anm. 4), 51f. (auch in Österreich gehörten die meisten Frauenhofmeister dem herzoglichen Rat an).

${ }^{71}$ Als commissor tritt er allerdings relativ spät in Erscheinung. Die ersten Beispiele datieren erst von 1353. Damals dürfte er nicht mehr Hofmeister gewesen sein (s. S. 95).

72 Z. B. HHStA, Cod. R. 55, Nr. 138 (1343 März 14, Meran): Pfandverschreibung für Konrad von Schenna.

${ }^{73}$ Z. B. TLA, Cod. 109, Nr. 96 und Nr. 97 (beide 1356 Februar 5, Tirol).

${ }^{74}$... sub sigillo Horenbeck. TLA, Cod. 129, Nr. 267 (Notiz; 1346 Juni 29, Wasserburg), und ... sub sigillo Horenbecken; ebd., Nr. 308 (Notiz; undatiert). Bezeichnenderweise ist er nach 1348 als Siegler nicht mehr erwähnt. Seit Herbst 1348 gab es nämlich unter der Hauptmannschaft Herzog Konrads von Teck eine eigene tirolische Kanzlei, die im Besitz eines landesfürstlichen Siegels war und auch in Abwesenheit Ludwigs Urkunden in dessen Namen ausstellen und beglaubigen konnte; vgl. Hörmann (wie in Anm. 2), 297-301. Weiters hatte Hornbeck offenbar die Befugnis, im eigenen Namen Urkunden für landesfürstliche Angelegenheiten auszustellen. Dies zeigen Erwähnungen in den Raitbüchern (z. B. TLA, Cod. 288, fol. $42^{\mathrm{v}}$ : ... per unam litteram Hornpechonis, oder fol. 53: Item dedit per V litteras Hornpechonis ...). Das ist in so ferne bemerkenswert, als zwar auch andere Räte Ludwigs landesfürstliche Urkunden ausstellen, aber nie im eigenen, sondern immer im Namen des Landesfürsten (als commissores); vgl. Anm. 41.

75 BHStA, Kurbayern, Äußeres Archiv (künftig KÄA), Cod. 1155/4, fol. 254 (1354 November 30, Innsbruck); vgl. Schmidbauer (wie in Anm. 14), Nr. 555; A. Huber, Geschichte der Vereinigung Tirols mit Österreich und der vorbereitenden Ereignisse. Innsbruck 1864, Nr. 172 und Nr. 173.

${ }^{76}$ Dazu vgl. Haug (wie in Anm. 49), Bd. 4, 42-45; Huber (wie in Anm. 75), 61f., und Nr. 166, 168-176. 
Gegenleistung für seine treuen Dienste bzw. zur Begleichung ihrer Schulden übertrugen ihm Ludwig und Margarethe in Nachfolge des verstorbenen Landeshauptmannes Konrad von Schenna 1346 Burg und Gericht Landeck ${ }^{77}$.

Seit seinem Engagement in Oberbayern scheint Gebhard in tirolischen Quellen nicht mehr auf, und im September 1360 hören wir das letzte Mal von ihm ${ }^{78}$. Das Amt des Hofmeisters der Landesfürstin dürfte er schon 1347, also lange vor seiner Bestellung in den Rat des bayerischen Hauptmanns, abgegeben haben ${ }^{79}$. Ende dieses Jahres ist er nämlich das letzte Mal in der Funktion eines Frauenhofmeisters genannt ${ }^{80}$. Möglicherweise hat er das Amt aber noch früher abgegeben, da Hans von Greifenstein bereits im März 1347 als Hofmeister in der Zeugenliste zweier Raitungen erwähnt ist ${ }^{81}$. Wie lange dieser dem Hofstaat Margarethes angehörte, lässt sich nicht eruieren - nach 1347 ist der Greifensteiner jedenfalls nicht mehr in dieser Funktion belegt ${ }^{82}$. Spätestens im März 1352 war der Jägermeister Konrad Kummersbrucker gleichzeitig auch Hofmeister der Herzogin ${ }^{83}$. Wie der Greifensteiner ist jedoch auch er nur selten in diesem Amt in den Quellen belegt, nämlich nur noch zweimal, Anfang 1358 und Ende 1359 ${ }^{84}$. Als Frauenhofmeister sind beide demzufolge nicht sonderlich in Erscheinung getreten.

77 Urkundenabschrift in HHStA, Cod. Bl. 127, Nr. 49 (1346 März 2, Bozen), und Notiz in HHStA, Cod. R. 55, Nr. 144a (undatiert). Das Richteramt in Landeck hat Gebhard allerdings nur kurz ausgeübt, da bereits ab August 1347 Wolfhard Satzenhofer in dieser Funktion Geldanweisungen erhält. TLA, Cod. 129, fol. 16 ${ }^{\mathrm{v}}$, Nr. 136-139.

${ }^{78}$ BHStA, KÄA, Cod. 4843, Nr. 283 (gestrichene Urkundenabschrift; 1360 September 26, München): Gebhard ist Zeuge bei einer Rechnungslegung mit dem bayerischen Vitztum Degenhard Hofer.

${ }^{79}$ Vielleicht hat er sich schon 1344 oder 1345 kurzfristig vertreten lassen. In diesem Sinne könnte man zumindest die Erwähnung Johanns von Schlandersberg als magister curie domine in einer Raitung Berchtolds, Richter in Passeier, für die Jahre 1344/45 verstehen (TLA, Cod. 62, fol. 198 ${ }^{\mathrm{r}}$ ). In derselben Raitung ist übrigens auch Hornbeck mehrfach als Hofmeister der Herzogin genannt (vgl. z. B. Anm. 86).

${ }^{80}$ TLA, Cod. 129, Nr. 367 (1347 November 30, Tirol).

${ }^{81}$ Gemeinsam mit seinem Bruder Friedrich; TLA, Cod. 62, fol. $199^{\mathrm{r}}$ und fol. $200^{\mathrm{v}}$ (beide 1347 März 4, Meran).

${ }^{82}$ Im Mai 1347 wird der Greifensteiner noch einmal als Hofmeister in einer landesfürstlichen Urkunde tituliert. HöLzL-Moser (wie in Anm. 59), Nr. 92.

${ }^{83}$ HHStA, Cod. Bl. 129, Nr. 57aa (Notiz; 1352 März 30, ohne Ortsangabe).

${ }^{84}$ BHStA, KÄA, Cod. 1155/3, pag. 409/1 (gestrichene Urkundenabschrift; 1358 Februar 27, München): Ludwig von Brandenburg erlaubt dem Jägermeister und Hofmeister der Herzogin Margarethe, auf dem Berg in Kundl (Kuntel) eine Burg 
Der Aufgabenbereich Gebhards als Hofmeister der Landesfürstin ist schwer greifbar. Lassen sich doch seine Tätigkeiten im Auftrag Ludwigs und als Leiter des Hofstaates der Margarethe schwer trennen. Dennoch wissen wir wesentlich mehr über ihn als über sein weibliches Pendant Beatrix. Die Erwähnungen in den beiden erhaltenen Raitbüchern und die Rechnungsanweisungen in den Registern dürften darauf hinweisen - auch wenn nicht explizit ausgewiesen -, dass Hornbeck in seiner Eigenschaft als Hofmeister in erster Linie für die Finanzen des Hofstaates zuständig war ${ }^{85}$. Häufig musste er auch selbst Gelder vorstrecken $^{86}$.

Über seine familiären Verhältnisse geben die Quellen begrenzt Auskunft. Wir erfahren nur, dass er einen Bruder hatte, Konrad Hornbeck ${ }^{87}$, der offenbar gemeinsam mit Gebhard Kaiser Ludwig den Bayern bei seinem Besuch in Tirol 1346 begleitet und dafür ein Streitross als Lohn

zu bauen, unter der Bedingung, sie von ihm, Ludwig, zu Lehen zu nehmen; vgl. auch Huber (wie in Anm. 75), Nr. 205 und Nr. 229 (1359 Dezember 20: Herzog Rudolf von Österreich behaust Konrad Kummersbrucker, den Jägermeister und Hofmeister der Markgräfin Margarethe, auf Widerruf mit der Burg zu Stein). $\mathrm{Zu}$ Kummersbrucker, der zu den wichtigsten und einflussreichsten Vertrauensleuten Ludwigs gehörte, ausführlich H. Bachmann, Ritter Konrad Kummersbrukker, Jägermeister in Oberbayern, und sein Urbar. Tiroler Heimat 43/44 (1979/80), $7-131$.

${ }^{85}$ In den Raitbüchern ist er häufiger in Zusammenhang mit Auslagen für die Herzogin erwähnt, wohingegen in den Registern sich die Geldanweisungen an ihn in der Regel nicht von anderen unterscheiden. Eine Ausnahme: HHStA, Cod. B1. 127, Nr. 87 (1346 März 26, Tirol): Markgraf Ludwig schuldet Gebhard Hornbeck, Hofmeister seiner Gemahlin, 400 Mark Berner, darumb er uns und unser gemaheln chost auzgenomen und verdient hat an Meran ... .

${ }^{86}$ Aus der Fülle der Belege können nur Beispiele erwähnt werden: TLA, Cod. 288, fol. 14 ${ }^{r}$ (aus einer Raitung Konrads von Schenna für die Jahre 1343/44): Item et tempore magistri curie domine dicti Hornpek dedit (= der Rechnungsleger) ioculatoribus libras XX. Ebd., fol. 22 (aus einer Raitung der Haller Salzmeier für die Jahre 1344/45): Item dominus Gebhardus Hornpek magister curie domine ad peticionem domini marchionis excredidit domino et domine in Insprukka in anno XLIII ... ; TLA, Cod. 62, fol. 197 (aus einer Raitung Berchtolds, Richter in Passeier, für die Jahre 1344/45): ... et pro expensis factis per dominum Gebh(ardum) Hornpek magistrum curie domine ... .

${ }^{87}$ HHStA, Cod. Bl. 127, Nr. 87 (1346 März 26, Tirol; vgl. Anm. 85): Ludwig schuldet Gebhard Hornbeck u. a. 40 Mark Berner für vier Hengste, von denen Ludwig einen Chützen dem Horenbecken seinem prúder gegeben hat. Weiters BHStA, KÄA, Cod. 1155/3, pag. 220/1 (1353 September 21, München): Ludwig von Brandenburg bestätigt Gebhard von Hornbeck auf dessen Bitten eine - inserierte Pfandurkunde, die dieser und sein Bruder Konrad 1347 April 7 in Brixen von Kaiser Ludwig IV. bekommen haben. 
empfangen hat ${ }^{88}$. Möglicherweise stand dieser Konrad in kaiserlichen Diensten. Einmal werden Auslagen für eine Übernachtung für die Diener ${ }^{89}$ und Pferde Gebhard Hornbecks et fratris sui ${ }^{90}$ verrechnet. Einmal hat Gebhard für seinen Neffen (nepos) Wolfhard Geld für ein Schwert ausgelegt ${ }^{91}$. Mehr als diese zufälligen und nicht sehr aufschlussreichen Erwähnungen hat sich über die Familienzusammenhänge dieses Hofmeisters nichts erhalten. Dafür geben die Quellen ein Detail aus seinem Leben preis, das insofern bemerkenswert erscheint, als solche Nachrichten nur selten und nur zufällig überliefert sind: Gebhard von Hornbeck litt 1346 offenbar an einer Augenkrankheit, die behandelt werden musste. Dass die Kosten dafür in landesfürstlichen Abrechnungen aufscheinen, zeigt, dass die ,öffentliche Hand' in Person des Tiroler Landesfürsten dafür aufgekommen ist ${ }^{92}$ - ein Vorläufer des heutigen Sozialsystems?

Resümierend sei festgehalten, dass die beiden ,Spitzenbeamten“ des Hofes der Landesfürstin, Hofmeisterin und Hofmeister, in den Quellen klar hervortreten; als Hofmeisterin ist allerdings nur Beatrix Moretscher namentlich bekannt, und auch im Amt des Hofmeisters tritt lediglich

${ }^{88}$ TLA, Cod. 129, Nr. 38 und 39 (1346 August 6, Innsbruck): Item habet (Petermann von Schenna) litteram unam pro marcis $L X X$ pro dextrario ab eo recepto et dato Chúnr(ado) Horenbecken. Item pro expensis domino imperatori datis in introitu et exitu ipsius in Matray ....

89 Dass Gebhard von Hornbeck eine eigene Dienerschaft hatte, ist für einen Mann in seiner Position naheliegend. Ein Diener lässt sich auch namentlich festmachen: Petermann von Schenna soll nach Anweisung Ludwigs dem Diener des Hornbeck, Seitz, 21 Mark Berner für fünf Fuder Wein auszahlen. TLA, Cod. 129, Nr. 45 (Notiz; 1347 November 27, Tirol). Weiters: TLA, Cod. 288, fol. $12^{v}$ (aus einer Raitung des Schine von Florenz 1342/43): Item famulis magistri curie domine libras $X X X$.

90 TLA, Cod. 62, fol. 189' (aus einer Raitung Daniels, Richter in Kastelbell, 1344 August 31, Meran, für die Jahre 1342/43).

${ }_{91}$ TLA, Cod. 288, fol $9^{v}$ (aus einer Raitung des Schine von Florenz für die Jahre 1342/43). Zur Person des Schine von Florenz vgl. J. Hörmans, Schine, Salzmeier von Hall. Zu Karriere und Biographie eines Florentiners im Tirol des 14. Jahrhunderts. Geschichte und Region 11 (2002), 137-153.

${ }_{92}$ TLA, Cod. 62, fol. 206 ${ }^{\mathrm{v}}$ (aus der Raitung des Haupold, Richter in Passeier, von 1349 Jänner 12, Meran; die Belege umfassen die Jahre 1346-48): Item dedit ad expensas domini et domine in Passira ... inclusis marcas XXII datis Hornpechoni medicando occulum suum. TLA, Cod. 129, Nr. 107 (1346 Juni 5, Meran): In dieser Notiz werden wiederum Ausgaben der Herrschaft im Passeier genannt und die 22 Mark, die nötig waren, dass Gebhard von Hornbeck in oculo curabatur; erwähnt bei O. SтоLz, Der geschichtliche Inhalt der Rechnungsbücher der Tiroler Landesfürsten von 1288-1350 (Schlern-Schriften 175). Innsbruck 1957, 63. 
Gebhard von Hornbeck deutlicher in Erscheinung. Beide stammen nicht aus dem heimischen Adel; Beatrix ließ sich jedoch durch ihre Heirat mit Dietrich Moretscher im Land nieder, wohingegen Gebhard, als sich für ihn in Bayern bessere Chancen boten, Tirol den Rücken kehrte. Ihr spezifisches, durch ihren Dienst bedingtes Aufgabengebiet lässt sich anhand der vorliegenden Nachrichten jedoch nicht umreißen. Vielmehr entsprechen die Zusammenhänge, in denen sie genannt werden, dem üblichen Schema, und ihre Nennungen stehen kaum im Kontext der Landesfürstin. Es ist jedoch davon auszugehen, dass ihre Agenden sich nicht wesentlich von jenen an anderen Höfen unterschieden haben und sich durchaus mit den Bestimmungen in den - späteren - Hofordnungen vergleichen lassen ${ }^{93}$.

\section{Dienerinnen und Diener}

Wer gehörte nun aber konkret zum Kreis jener Personen, für die Hofmeisterin und Hofmeister im Namen der Landesfürstin die Verantwortung trugen? Auch wenn die Quellenlage vergleichsweise gut ist, so muss doch einschränkend bemerkt werden, dass der Aussagekraft der gesammelten Informationen Grenzen gesetzt sind. Denn, so vielfältig die Nachrichten auch sind, so zufällig und willkürlich sind sie überliefert. Man erfährt zwar Namen, Ämter und Funktionen, nicht jedoch die Struktur und Organisation, die dem Hofstaat zugrunde lagen. Auch von einer nur annähernden Vollständigkeit des feststellbaren ,Personalstandes' ist nicht auszugehen. Dennoch vermag die Summe des Materials ein zumindest ungefähres Bild zu bieten.

Zunächst sei noch einmal festgehalten, dass zum Hof der Landesfürstin Frauen wie Männer gehörten. Wie auch bei Konrad von Megenberg allgemein angeführt ${ }^{94}$, zählten zum engeren Kreis der weiblichen Dienerschaft die domicelle bzw. die „Jungfrauen“95, meist junge Frauen, die der Landesfürstin wohl in erster Linie zur Unterhaltung und Repräsentation dienten. Sie sind die Vorläuferinnen der späteren Hofdamen und waren wohl in der Regel adeliger Herkunft. Neben der

\footnotetext{
${ }^{93}$ S. oben S. 85.

${ }^{94}$ Megenberg (wie in Anm. 21), I, 258-260 (er nennt die Hofdamen puellae oder ancillae maiores); Drossbach (wie in Anm. 21), 114. Ausführlich auf die Höfe der habsburgischen Herzoginnen in Österreich geht Müller (wie in Anm. 11), 654665 ein.

95 Vgl. Rösener (wie in Anm. 15), 198, Anm. 113.
} 
kursorischen Nennung von domicelle ${ }^{96}$ und „Jungfrauen“97 begegnen namentlich in dieser Position: Petel Wulf ${ }^{98}$, Margarete Bucher ${ }^{99}$ und Katharina Bucher ${ }^{100}$, Wandelburg die Aschauerin ${ }^{101}$, Katherina Stau-

${ }_{96}$ Z. B. HHStA, Cod. Bl. 126, Nr. 39 (Notiz; undatiert): Item obligatus est Eb(er)hardo dicto Cholb de marcis LXXXX pro pannis domino, domine et domicellabus. TLA, Cod. 288, fol. $9^{v}$ (aus einer Raitung des Schine von Florenz, 1342/43): Item dedit pro expensis domicellabus domine, que remanserunt infirme post introitum domine in Athesim. Ebd., fol. 14 (aus einer Raitung des Konrad von Schenna 1343/44): Item et exsolvit unum palleum purpureum domine et duo pallea domicellarum domine aput Christanu(m) dictum Layt(er) de Insp(ruck) pro libris $X L$.

${ }_{97}$ BHStA, KÄA, Cod. 1155/3, Nr. 417/2 (1358 März 22, München): Ludwig von Brandenburg schuldet dem Münchner Bürger Heinrich Rud 240 Münchner Pfennige, u. a. für Gewand, das er der Herzogin Margarethe, den Jungfrauen und dem Hofmeister gegeben hat.

${ }^{98}$ HHStA, Cod. Bl. 126, Nr. 43 (Notiz; 1343): Item magistro Martino physico pro labore, quo habuit cum domicella dicta Petel Wulfin in infirmitate sua ... . Bei S. voN Mayrhofen, Genealogien des tirolischen Adels. Erloschene Geschlechter 6. Manuskript im Tiroler Landesmuseum Ferdinandeum, Nr. 48, ist in der Stammtafel der Herren von Reifenstein, respektive der Wölfe von Mareit (Wulf $=$ Wolf?) Petlina, Tochter des Heinrich von Mareit, erwähnt. Vielleicht ist sie mit jener domicella Petel identisch. Zu den Wölfen von Mareit allgemein M. HörmannWeingartner, Wolfsthurn, in: Tiroler Burgenbuch 3: Wipptal, hrsg. von O. Trapp. Innsbruck-Bozen-Wien 1974, 189-233, bes. 190f.

${ }_{99}$ HHStA, Cod. Bl. 129, Nr. 49 (1350 April 4, Tirol): Ludwig von Brandenburg schuldet Margar(ete) der Búcherin, unser lieben gemaheln junchfrawn, für die versprochene Heimsteuer anlässlich ihrer Eheschließung mit Jakob Goldegger 300 Mark Berner, die er ihr auf die äußere und innere Steuer und auf den Zinspfennig von Bozen aufschlägt. TLA, Cod. 129, Nr. 286 (Notiz; 1347 September 17, Hall): ... et pro panno domicellarum domine videlicet Gretel de W(er) et Puch(er)in empto .... .

100 Hölzl-Moser (wie in Anm. 59), Nr. 131 (1351 November 11, Brugg): Ludwig von Brandenburg schuldet den Jungfrauen seiner Frau, Katharina Bucher und deren Schwester, Frau des Lorenz Plätscher, 100 Mark Berner an Heimsteuer und lässt ihnen dafür genannte Güter verschreiben. Diese Schwester kann nicht mit Margarethe Bucher identisch sein, da diese sich mit Jakob Goldegg verheiratete (s. Anm. 99).

${ }^{101}$ HHStA, Cod. Bl. 129, Nr. 69 (1350 November 3, Tirol): Ludwig von Brandenburg bestätigt mit Zustimmung der Herzogin Margarethe seinem Getreuen Wilhelm von Enn und dessen zukünftiger Gemahlin Wandelburg der Aschaw(er)in, unser vorgennanten gemacheln junchfrawen, die wir im gelobt haben und geben ze ainer elichen husfrawen alle Urkunden und Briefe, die Wilhelm von seiner verstorbenen Frau Floridiana genant Sigaun über die Burg Forst bekommen hat. Diese hatte die Burg von ihrem verstorbenen ersten Mann Albert von Camian, einem natürlichen Sohn Heinrichs, Titularkönigs von Böhmen, als landesfürstliches Lehen geerbt. Vgl. O. Trapp, Forst, in: Tiroler Burgenbuch 2 (wie in Anm. 69), 225-230, 
fer ${ }^{102}$, Gretel von Wer ${ }^{103}$, Agnes Gnausch ${ }^{104}$, die Keterlein ${ }^{105}$, Margarethe, Tochter des H. ${ }^{106}$, Berta Marschalk ${ }^{107}$, die Rutenbergerin ${ }^{108}$ und Beatrix Hessenacker ${ }^{109}$. Diese Nennungen stehen zum großen Teil in Zusammen-

bes. 225. Wilhelm III. von Enn war unter Ludwig von Brandenburg Richter in Schlanders und kommt in dieser Funktion häufig in den Registern vor. МayrhoFEN (wie in Anm. 98), 3, Nr. 38: Sigune von Forst ist aber nicht die Mutter, wie in der Stammtafel verzeichnet, sondern die erste Frau Wilhelms III.

${ }^{102}$ HHStA, Cod. Bl. 129, Nr. 61 a (1352 Februar 13, ohne Ortsangabe): Ludwig von Brandenburg gibt Kathereinen der Stauf(er)inne, unser lieben gemacheln junchfrawen, die er Heinrich dem Gerenstain(er) (Garnstein) zur Frau gegeben hat, als Heimsteuer 300 Mark Berner, die er ihnen auf die äußere und innere Steuer sowie den Zinspfennig von Bozen aufschlägt.

103 TLA, Cod. 129, Nr. 286 (Notiz; 1347 September 18, Hall): vgl. Anm. 99. Eine um 1418 verstorbene Margarethe von Weer (die Herren von Weer waren zunächst andechsische, dann tirol-görzische Ministerialen) ist bei Mayrhofen (wie in Anm. 98), 7, Nr. 74 erwähnt. Da sie aber erst um 1418 verstorben ist, kann sie kaum mit der erwähnten domicella Grete identisch sein. M. Bitschnau, Burg und Adel in Tirol zwischen 1050 und 1300. Grundlagen zu ihrer Erforschung (SB $\ddot{O A W}$, phil.-hist. Klasse 403). Wien 1983, Nr. 597.

104 TLA, Cod. 109, Nr. 17 (1355 Juli 4, München): Ludwig von Brandenburg schuldet seinem Getreuen Dietel dem Hofer 400 Mark Berner für das Heiratsgut, das Ludwig ihm anlässlich seiner Eheschließung mit Agnesen der Gnawschinne [wilant gestrichen ] etwanne unsrer gemacheln junchfrawe gegeben hat und verspricht, die Summe bis kommende Lichtmess zu bezahlen.

105 TLA, Cod. 109, Nr. 182 (1354 Oktober 7, Mittenwald): Ludwig von Brandenburg schuldet Johann Ligsalz, Bürger von München, genannte Geldsummen, für die er u. a. .. der graefinn uz Ultem, Rudig(er)s Stockel tochter, und Keterlein, unsrer gemaheln junckfrouwen, 41 Tage lang verköstigt hat.

${ }^{106}$ Der Name des Vaters ist wegen eines Tintenflecks nicht lesbar. BHStA, KÄA, Cod. 4843, Nr. 1 (1355 November 24, Tirol): Ludwig von Brandenburg gibt Margar(ete) $H$. des (Tintenfleck) tohter, unserr gemahelen .. der M(argarete) junchfra(ue)n, 300 Münchner Pfennige zur Heimsteuer anlässlich ihrer Eheschließung mit Ulr(ich) dem Ahdorff(er).

107 BHStA, KÄA, Cod. 4843, Nr. 2 (1356 Jänner 13, Tirol): Ludwig von Brandenburg schuldet Otto von Ruesenbach 100 Mark Berner, die Ludwig ihm zur Heimsteuer anlässlich der Eheschließung mit Berchten der Marschalkinn, unserer gemaheln junchfrawen, gegeben hat und versetzt ihm dafür die landesfürstlichen Rechte im Dorf Münster. Ebd., Nr. 3 (1356 Jänner 13, Tirol): Ludwig von Brandenburg schuldet demselben wegen der genannten Hochzeit mit Berchten der Marschalkinne 230 Meraner Münze an Heimsteuer und verschafft ihm das Geld auf die Opferpfennige, die Ludwig jährlich zu Weihnachten aus dem großen Zoll in München bekommt.

108 TLA, Cod. 109, Nr. 65aa (fol. 29v) (Raitung, undatiert): Item pro equo domicelle Rútinberg(er)inn ex parte domine obligato VII marcas.

109 Vgl. BHStA, KÄA, Cod. 1155/3, pag. 135/1 (1353 April 24, Meran): Ludwig von Brandenburg garantiert seinem Getreuen Heinrich Vorster, bis Jahresfrist als 
hang mit Vergünstigungen meist finanzieller Natur, die die Höflinge aufgrund ihrer treuen Dienste bekommen haben. Das Nahverhältnis zur Herrschaft zeigt sich auch darin, dass jene, die in den Stand der Ehe traten, vom Landesfürsten - bezeichnenderweise nicht von der Landesfürstin als der eigentlichen Dienstgeberin ${ }^{110}$ - jeweils mit einer Mitgift ausgestattet wurden. Für die gehobenere soziale Stellung der ,Jungfrauen" spricht, dass die Männer, mit denen sie sich verheirateten, eine entsprechende gesellschaftliche Position innehatten ${ }^{111}$ und in der Regel Vertrauensleute des Markgrafen waren. Die Sorge um das Wohlergehen der eigenen Dienerschaft wird auch hier deutlich: mehrfach werden in den Rechnungsbüchern Gelder verbucht, die für die ärztliche Behandlung kranker domicelle ausgegeben wurden ${ }^{112}$.

Heiratsgut und Heimsteuer für die Eheschließung mit Petrisen der Hessenack(er), unsrer lieben gemaheln juenckfrawen, 300 Mark Berner und für vertigunge 40 Mark Berner zu geben.

110 So war es beispielsweise auch an den habsburgischen Höfen üblich; vgl. LackNER (wie in Anm. 4), 52f.

111 Vgl. z. B. die Formulierung unser lieber getrewer; s. Anm. 101, 104, 109. Wilhelm von Enn (Anm. 101), Heinrich Garnstein (Anm. 102) und auch Rudolf Milser (Anm. 112) gehörten alle Tiroler Ministerialenfamilien an; die soziale Herkunft Heinrich Vorsters (Anm. 109) bleibt hingegen unklar. Ein Verwandtschaftsverhältnis mit dem nach Mayrhofen kinderlosen Albert von Camian-Forst, einem unehelichen Bruder der Herzogin Margarethe, lässt sich jedenfalls nicht konstruieren, ist jedoch nicht grundsätzlich auszuschließen. Mayrhofen (wie in Anm. 98), 7, Nr. 55.

112 Vgl. Anm. 96, 98; weitere Beispiele: TLA, Cod. 288, fol. 22 (aus einer Raitung der Haller Salzmeier von 1344/45): Item dedit magistro Hainr (ico) visico de Hallis visitanti domicellas domine in monte sancti Pet(ri), que erant infirme pro labore suo libras $X$. Auch für die Jungfrauen der verstorbenen Vorgängerinnen Margarethes wurde gesorgt: z. B. HHStA, Cod. R. 55, Nr. 43 (1342 Juli 24, Innsbruck): Ludwig bestätigt Margreten, der ehemaligen Jungfrau der Herzogin Adelheid von Braunschweig und Witwe des Rudolf Muelser (Milser von Klamm), finanzielle Zuwendungen, die ihr von König Heinrich zugedacht worden waren; zu Rudolf Milser und seiner Frau Margret vgl. die Stammtafel bei Mayrhofen (wie Anm. 98), 5, Nr. 55; weiters HHStA, Cod. R. 55, Nr. 51 (1342 August 15, Innsbruck): Ludwig weist den Haller Salzmeier Schine an, Wandeln, der Tochter der Sophia, der ehemaligen Dienerin der Königin Anna (gest. 1313), sowie deren Mann, Hainr(ich) dem Scheryen, ab Michaeli alle Jahre 20 Mark Berner so lange zu geben und zu verrechnen, bis die 70 Mark bezahlt sind, die sie von der Königin Anna noch hätten bekommen sollen, wobei sie im letzten Jahr nur mehr zehn Mark bekommen; vgl. auch TLA, Cod. 129, Nr. 263 (Notiz; 1346 Mai 25, Innsbruck). 
Neben den „Jungfrauen“ sind auch einige wenige Dienerinnen namentlich erwähnt, wie Mechthild, die sich mit Heinrich Huttingen von Zirl verheiratete ${ }^{113}$, und Margarethe die Böhmin (Behamin $)^{114}$. Die großzügige Unterstützung, die ihnen von Seiten des Landesfürsten zuteil wurde, und die Titulierung der Mechthild als erber fraw lässt vermuten, dass es sich auch bei diesen um höhergestellte Frauen handelt, die in Diensten der Fürstin standen, aber keine Dienerinnen im herkömmlichen Sinn waren.

Das männliche Pendant zur domicella war der domicellus, zu deutsch am ehesten mit „Junker“"115, ,Jungherr“ oder „Knappe“ zu übersetzen, Bezeichnungen, die in den Tiroler Belegen aber kaum verwendet wurden ${ }^{116}$. Ansonsten steht in den deutschen Texten allgemein stets diener, was eine Differenzierung in der Hierarchie erheblich erschwert. Darüber hinaus wird auch in den lateinischen Texten nicht eindeutig zwischen domicellus, familiaris und famulus unterschieden. Ein Matthias zum Beispiel wird sowohl als domicellus als auch als diener bzw. familiaris bezeichnet, desgleichen Kunz Wolflin u. a. m. Diese vermischte Verwendung der Begriffe mag darauf hinweisen, dass auch in der Funktion der domicellus mit dem diener bzw. famulus gleichzusetzen ist. Auch bei den männlichen Dienern lässt sich die adelige Standesqualität häufig - nicht immer nachweisen. In Diensten der Landesfürstin zu stehen war demnach vor

${ }^{113}$ HHStA, Cod. Bl. 127, Nr. 11 (1344 September 9, Innsbruck): Ludwig von Brandenburg bestätigt der erbern frawen Mehthilten, ... unser lieben gemahelen dienerin, die 40 Mark Heimsteuer und Morgengabe und weitere zehn Mark, die sie von ihrem Mann bekommen hat, nach der Urkunde, die sie Ludwig und dem Rat darüber vorlegte.

114 TLA, Cod. 109, Nr. 169 (1356 September 16, Tirol): Ludwig von Brandenburg verleiht Margar (ete) dew Behaminne für die Dienste, die sie lang zeit getan hat an unserer gemacheln der margravinne und an irer swester, zwei Fuder Weingeld aus einem Hof in Algund auf Lebenszeit. Weiters ebd., Nr. 403 (1355 Mai 29, Tirol): Ludwig von Brandenburg verleiht Margr(eten) der Pehaiminne aus demselben Grund zwei Fuder Weingeld aus der Vogtei Riffian auf Lebenszeit. Der Zuname Böhmin lässt darauf schließen, dass diese Dienerin seit den Tagen der böhmischen Regierung in landesfürstlichen Diensten stand.

115 Vgl. E. Habel-F. Gröbel, Mittellateinisches Glossar. Paderborn ${ }^{2} 1989$. Die männliche Dienerschaft einer Fürstin fehlt in der Ämterliste des Konrad von Megenberg.

116 TLA, Urk. I 9560 a/3 (1342 September 30, Innsbruck): Herzogin Margarethe bittet Konrad von Schenna, dass er dieses Jahr (hewer) Chúnczen Wolflein unsern juncherren nicht mit ihrem Gemahl Ludwig auf Reisen schickt, sondern stattdessen den Überbringer dieses Briefes mit ihm fahren lässt [Ed. SperL (wie in Anm. 60), Nr. 13]. 
allem für den Tiroler Ministerialenadel attraktiv und wahrscheinlich auch mit sozialen Aufstiegsmöglichkeiten verbunden, gleichzeitig übten aber auch - soweit sich das aus den spärlichen Namensnennungen schlieBen lässt - Nichtadelige dieselben Funktionen aus und konnten Karriere machen.

Die Belege für die männliche Dienerschaft sind bezüglich der namentlichen Nennungen vergleichsweise zahlreich ${ }^{117}$ : Häufig begegnen die domicelli domine Wolflin von Mareit ${ }^{118}$ und Konrad (Kunz) Wolflin ${ }^{119}$, weiters Nikolaus Hauensteiner ${ }^{120}$, Johann Greif ${ }^{121}$, Johann Lichtenber-

117 Daher wird im Folgenden auf die vollständige Anführung der Belegstelle verzichtet. Zu den Karrieremöglichkeiten in Diensten der Tiroler Landesfürsten im 14. Jh. vgl. G. Pfeifer, Nobis servire tenebitur in armis. Formen des Aufstiegs und Übergangs in den niederen Adel im Tirol des 14. Jahrhunderts, in: Zwischen Nicht-Adel und Adel, hrsg. von K. Andermann-P. Johanek (Vorträge und Forschungen 52). Stuttgart 2001, 49-102.

118 Wolflin von Mareit gehörte zur Familie der Wölfe von Mareit, die seit 1242 den Turm in Mareit als Lehen innehatten. Ein Zweig der Familie hatte die Burg Reifenstein bei Sterzing zu Lehen. Bei Mayrhofen (wie in Anm. 98), 6, Nr. 48, ist ein Wolflin von Mareit als 1345 noch lebend erwähnt. Er war mit Elisabeth von Braunsberg verheiratet; vgl. Hörmann-Weingartner (wie in Anm. 98), 190f; Bitschnau (wie in Anm. 103), Nr. 126. Erwähnungen finden sich in den Raitbüchern TLA, Cod. 288 (z. B. fol. $9^{\mathrm{v}}, 11^{\mathrm{r}}, 56^{\mathrm{v}}$ ), und Cod. Nr. 62 (z. B. fol. 161 $1^{\mathrm{r}}, 163^{\mathrm{v}}$, $205^{r}$ ) zwischen 1342 und 1353.

119 Vgl. Anm. 118. Konrad der Wolf ist bei Mayrhofen, ebd., als Sohn des Heinrich Wolf erwähnt. Dieser Heinrich servitor domini in Burg Tirol heiratete 1312 Elisabeth, eine natürliche Tochter Herzog Meinhards II., wofür sie deren Bruder, Titularkönig Heinrich, mit einer entsprechenden Heimsteuer ausstattete. TLA, Cod. 18, fol. 7, und HHStA, Cod. R. 50, fol. $28^{\text {rv }}$ [ed. A. Zauner, Das älteste Tiroler Kanzleiregister 1308-1315 (Fontes Rerum Austriacarum 78). Wien 1967, Nr. 70 und 71]; Hörmann-Weingartner, ebd. Erwähnungen z. B. in TLA, Cod. 288, fol. $50^{\mathrm{r}}(1345-1352)$, und Cod. Nr. 62, fol. $207^{\mathrm{r}}(1346-1348)$, fol. $212^{\mathrm{r}}$ (13491351).

${ }^{120}$ Ein Nikolaus ist als Sohn des Albert von Hauenstein im Stammbaum der Familie bei Mayrhofen erwähnt (für die Jahre 1335 und 1342). Die Hauensteiner sind ursprünglich Brixner Ministerialen und werden seit 1286 als nobilis bezeichnet. Bitschnau (wie in Anm. 103), Nr. 273; K. Ausserer, Ruine Hauenstein. Studie über die ältere Geschichte des Schlosses mit einer Stammtafel der Hauensteiner. Der Schlern 6 (1925), 133-141, bes. 136; Mayrhofen (wie in Anm. 98), 4, Nr. 49; J. Gritsch, Hauenstein, in: Tiroler Burgenbuch 4: Eisacktal, hrsg. von O. TrapP. Bozen-Innsbruck-Wien 1977, 336-347, bes. 5f. TLA, Cod. 288, fol. 9v (1342/43) und fol. $22^{\mathrm{r}}(1344 / 45)$.

121 Ein Hans Greif von Mais (Meran) ist nach Mayrhofen (wie in Anm. 98), 4, Nr. 31, zwischen 1333 und 1358 nachweisbar. Er war Sohn des Jakob Greif von Haslach zu Obermais und zweimal verheiratet. Ursprünglich stammte die Familie aus Lana. Eine Erwähnung im TLA, Cod. 288, fol. 16 $6^{\text {r }}$ (1342-1344). 
ger ${ }^{122}$, Andreas Pfaffinger ${ }^{123}$, Albert ${ }^{124}$ und Matthias ${ }^{125}$.,Nur als familiaris domine bzw. „Diener" ausgewiesen sind Stephan Volraier ${ }^{126}$, Ortlin Freyenpuhler ${ }^{127}$, Heinrich Kuklinger ${ }^{128}$, Hans der Scherer ${ }^{129}$, ein gewisser Johann famulus domine, der vielleicht mit dem Diener Johann dem Vögler gleichzusetzen ist ${ }^{130}$, und Rudiger Stoklin von Eben ${ }^{131}$. Letzterer avancierte später zum Küchenmeister der Herzogin und erscheint in dieser Funktion mehrfach in den Registern (bis 1356) ${ }^{132}$. Johann Rasor war ursprüng-

${ }^{122}$ Johann II. von Lichtenberg (Burg im Obervinschgau) war Sohn des Johann I. von Lichtenberg und mit Luzia von Reichenberg verheiratet. Nach Mayrhofen (wie in Anm. 98), 5, Nr. 12, starb er vor 1353; vgl. Bitschnau (wie in Anm. 103), Nr. 373. Eine Erwähnung im TLA, Cod. 62, fol. 191 (1342/43).

${ }_{123}$ TLA, Cod. 288, fol. $43^{\text {r }}$ (1347/48), und Cod. Nr. 129, fol. $42^{\mathrm{v}}(1347 / 48)$.

124 TLA, Cod. 288, fol. $21^{\mathrm{v}}(1344 / 45)$, und Cod. Nr. 62, fol. 197 $(1343 / 44)$.

125 TLA, Cod. 288 , fol. $22^{\mathrm{r}}$, und fol. $22^{\mathrm{v}}(1344 / 45)$.

${ }^{126}$ Der Volraierhof liegt in der Gemeinde Naturns. TLA, Cod. 288, fol. $56^{\mathrm{v}}$ (1352/53), und Cod. Nr. 59, fol. 109r (1358 Jänner 7, Tirol).

127 TLA, Cod. 62, fol. $153^{\mathrm{v}}$ (1341).

128 TLA, Cod. 62 , fol. $157^{\mathrm{v}}(1340 / 41)$.

${ }^{129}$ HHStA, Cod. R. 55, fol. $45^{\mathrm{v}}$ (1343 Jänner 24, ohne Ortsangabe): Hans der Scherer, Ludwigs und Margarethes Diener.

130 TLA, Cod. 62, fol. 153b b $^{\mathrm{r}}$ (1341). TLA, P 2083 (1355 Februar 22, Burg Tirol): Herzogin Margarethe beauftragt die Haller Salzmeier, Johann dem Veglar, unserm diener, den Zins, den dieser jährlich bekommt, nicht zu vermindern [Ed. SPERl (wie in Anm. 60), Nr. 25].

${ }^{131}$ Z. B. TLA, Cod. 288, fol. $11^{\mathrm{v}}(1342 / 43), 42^{\mathrm{v}}(1347 / 48)$, Cod. 62 , fol. $205^{\mathrm{r}}(1347 / 48)$, und HHStA, Cod. Bl. 126, fol. $17^{\mathrm{r}}$ (1343). Einmal ist Rudiger auch als famulus domini bezeichnet; so genau hat man offenbar die Zuständigkeiten nicht voneinander getrennt (TLA, Cod. 62, fol. 185 ${ }^{\mathrm{r}}$, 1342/43); weiters Cod. Bl. 126, Nr. 44 (1343): Item Rúdig(eri)o Stócklein marcas $X$ in in [sic] subsidium unius spadonis de gracia speciali et in refusionem equi, quem perdit in servicio domine apud Botschonem. Die Stöckl sind ein Seitenzweig der Herren von Matrei, die bis 1337 den Burgberg in Matrei (später Raspenbühel) innehatten. Als tirolische Ministerialen standen sie häufig in landesfürstlichen Diensten. Heinrich Stöckl übte seit 1346 die Burghut über Schlossberg (bei Seefeld) aus und nennt sich von Eben (über seine Mutter, Tochter des Bero von Eben). Als Bruder des Heinrich nennt MaYRHofen (wie in Anm. 98), 7, Nr. 35, Rudeger Stöckl, Richter auf Hörtenberg, der um 1366 gestorben ist.; vgl. Steinberger (wie in Anm. 67), 179; O. Trapp, Raspenbühel, in: Tiroler Burgenbuch 3 (wie in Anm. 98), 20-22, bes. 20; M. BITschnau, Schlossberg, in: Tiroler Burgenbuch 6: Mittleres Inntal, hrsg. von O. Trapp. Innsbruck-Bozen-Wien 1982, 15-28, bes. $16 \mathrm{f}$.

132 Z. B. BHStA, KÄA, Cod. 1155/3, pag. 123/2 (1353 April 8, Bozen) und pag. 268/3 (Notiz; 1353 November 21, ohne Ortsangabe), BHStA, KÄA, Cod. 4842, Nr. 40 (1354 März 4, Bozen), TLA, Cod. 109, fol. 83 (Notiz; 1354 November 20, Innsbruck), und BHStA, KÄA, Cod. 1155/4, Nr. 308v/2 (Notiz; 1355 Dezember 8, Tirol). 
lich Diener des Mundschenks der Herzogin, ist auch einmal als subpincerna bezeichnet ${ }^{133}$ und wird spätestens 1347 zum Diener der Landesfürstin ,befördert ${ }^{\prime 134}$. Ulrich Knoblach, der erst 1356 als Diener genannt ist, erscheint in den 1340er Jahren mehrfach als sartor domine, also als Schneider Margarethes ${ }^{135}$.

Innerhalb der allgemeinen Erwähnungen der landesfürstlichen Dienerschaft bzw. des Hofgesindes (famuli domine, familia domine oder familiares $)^{136}$ gibt es in Einzelfällen Differenzierungen: So erfahren wir von den famuli pincernatus domine ${ }^{137}$, von den famuli camere ${ }^{138}$ oder subfamiliares camere domine ${ }^{139}$ und von einem famulus custodiens equum domine ${ }^{140}$. Der Stand der Ehe war für die männliche Dienerschaft kein Hindernis. Hans der Scherer zum Beispiel, ein Diener Ludwigs und Margarethes, war mit Irmgard verheiratet und bekam Anfang der 1340er Jahre von Ludwig ein Haus unterhalb der Burg Tirol mit zwei Gärten verliehen ${ }^{141}$.

Neben den domicelle und domicelli sowie der allgemeinen Dienerschaft, die in den deutschen Quellen meist als hofgesinde bezeichnet wird und in der Regel untergeordnete Arbeiten verrichtet haben dürfte - sei es direkt für die Landesfürstin, in der Kammer oder in der Küche -, hat es innerhalb des Hofstaates neben Hofmeister und Hofmeisterin auch noch weitere leitende Hofämter gegeben, die jeweils ihr Pendant im Hof-

${ }^{133}$ TLA, Cod. 62, fol. $185^{\mathrm{r}}$ (1342/43): subpincerna, fol. 193 (1343/44): famulus pincerne.

134 TLA, Cod. 129, fol. ??? (Notiz; 1347 Oktober 13, Matrei): familiaris domine. Dies ist gleichzeitig auch die letzte Erwähnung des Johann Rasor.

135 TLA, Cod. 59, fol. $76^{\text {r }}$ (1356 April 22, Tirol); als sartor: TLA, Cod. 288, fol. $43^{\text {r }}$ (1347/48), und Cod. Nr. 62, fol. 198 $(1344 / 45)$.

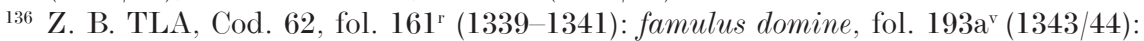
familia domine, fol. $197^{\mathrm{v}}$ (1344/45): familiares domine; TLA, Cod. 109, fol. 91 ${ }^{\mathrm{r}}$ (Notiz; 1354 Dezember 16, Glurns): Item famulis domine pro vestitu et calciis ...; BHStA, KÄA, Cod. 4843, Nr. 194 (gestrichene Urkundenabschrift; 1360 März 15, München): ...so hat er (Heinrich von Isny, Kellner auf Tirol) uns (Ludwig) und unserr gemaheln und unser baider hofgesinde ... .

137 Z. B. TLA, Cod. 288, fol. $22^{\text {r }}(1344 / 45)$.

${ }^{138}$ Z. B. TLA, Cod. 62 , fol. 154 (1342): famulis camere pro tunicis ... . Namentlich genannt ist Wernher famulus camere in ebd., fol. $180^{\mathrm{r}}(1342)$, wobei in beiden Fällen der Zusatz domine fehlt. Da aber die Auszahlung der Gelder über Urkunden Margarethes angewiesen wurde, ist der Schluss zulässig, dass es sich um Kammerdiener der Landesfürstin handelt.

139 Z. B. TLA, Cod. 288, fol. 32 $(1346 / 47)$.

140 TLA, Cod. 62, fol. 202 (1338-1344).

${ }^{141}$ HHStA, Cod. R. 55 (1343 Juni 24, ohne Ortsangabe). 
staat Ludwigs hatten ${ }^{142}$. So hatte auch Margarethe ihren Küchenmeister, Kämmerer, Marschall, Schenken und einen eigenen Türhüter. Zum „,Hofpersonal“ sind weiters auch die persönlichen Kapläne der Herzogin zu zählen, von denen drei, Rudolf von Winterthur, Heinrich und Ulrich, namentlich bekannt sind ${ }^{143}$. Eine wichtige Rolle im Hofgefüge der Landesfürstin spielte der Notar Friedrich von Mais, der schon unter ihrer Tante, Herzogin Eufemia, gedient hatte und von Margarethe nach deren Tod übernommen wurde.

\section{KÜCHENMEISTER}

Aufgabe des Küchenmeisters war die Versorgung, Verpflegung und Verköstigung des Hofstaates mit der Dienerschaft und dem Gesinde. Er war sozusagen für den Haushalt verantwortlich, kontrollierte den Verbrauch der Küche und ließ darüber Buch führen. Auch die Anstellung der Köche und anderer Küchenbediensteter oblag seinem Aufgabenbereich $^{144}$. Im Fall des magister coquine domine war der Aufgabenbereich naturgemäß auf den Hof der Landesfürstin beschränkt.

${ }^{142}$ Der Einfluss der Inhaber der Hofämter Ludwigs, meist auch Mitglieder des landesfürstlichen Rates, war in der Regel jedoch ungleich größer. Das zeigt sich allein in der stärkeren Quellenpräsenz. Beispielsweise begegnet außer dem Hofmeister der Margarethe keiner ihrer ,Leute' in den commissor-Vermerken und in den Zeugenlisten der Rechnungslegungen. Zu den Amtsinhabern vgl. SchмidbauER (wie in Anm. 14), 103-145.

${ }^{143}$ Ein Kaplan Heinrich ist in einer Raitung der Jahre 1342-1350 (TLA, Cod. 62, fol. 208ar) belegt, Kaplan Ulrich in einer Notiz von 1360 Mai 13 (HHStA, Cod. W. 209, Nr. 570). Am 9. Mai 1346 folgt Rudolf von Winterthur, Kaplan der Herzogin Margarethe, dem verstorbenen Pfarrer Dietrich als Pfarrer der Kirchen von Absam nach. Weiters bestätigt der Landesfürst am 4. August Rudolf, dem Kaplan Margarethes und Pfarrer der Kirchen von Absam und Hall, die dessen Vorgänger von König Heinrich und Margarethe verliehenen Rechte. Hall, Pfarrarchiv, Nr. 35 und Nr. 36; Ed.: H. Moser, Die Urkunden der Pfarre Hall in Tirol 1281-1780 (Tiroler Geschichtsquellen 39). Innsbruck 1998, Nr. 35 und 36; in BHStA, KÄA, Cod. 1155/3, Nr. 252/3 ist zum Datum 1353 Oktober 23 ein capellanus domine ohne Namensnennung erwähnt.

144 Allgemein zu den Aufgaben des Küchenmeisters Megenberg (wie in Anm. 21), I, 162-164; Lackner (wie in Anm. 4), 83f.; Streich (wie in Anm. 11), 375-380; H. Spangenberg, Hof- und Zentralverwaltung der Mark Brandenburg im Mittelalter (Veröffentlichungen des Vereins für Geschichte der Mark Brandenburg). Leipzig 1908, 48 . 
In dieser Funktion ist 1343 der Ncerrenpecker erwähnt ${ }^{145}$ und - wahrscheinlich als sein Nachfolger - Eberhard, magister coquine domine, der in einer Raitung des Propstes von Mais aus dem Jahr 1345 genannt ist ${ }^{146}$. Der bereits erwähnte ehemalige Diener Rudiger Stöckl hat nach den Belegstellen das Hofamt 1353 bis 1356 bekleidet ${ }^{147}$.

Die Bedeutung des magister coquine der Landesfürstin kann wohl nicht mit jener des landesfürstlichen Küchenmeisters verglichen werden. Zwar erscheint auch Rudiger Stöckl, der als einziger mehrfach Erwähnung gefunden hat, stets in Zusammenhang mit finanziellen Angelegenheiten, dies gilt jedoch auch für die Inhaber anderer Ämter. Außerdem gehören Geldzahlungen generell zu den vorwiegenden Betreffen in den Raitbüchern und Registern, daher ist dieser Kontext nicht weiter ungewöhnlich. Das Amt des landesfürstlichen Küchenmeisters, das jahrelang Berthold von Ebenhausen und nach ihm Konrad Frauenberger, beide bayerische Gefolgsleute Ludwigs, bekleideten, gehörte dagegen zu den höchsten und einflussreichsten am Hof. Das zeigt sich an ihren häufigen Erwähnungen in den commissor-Vermerken und in den Zeugenlisten der Rechnungslegungen sowie an den zahlreichen Geldanweisungen, die an den Küchenmeister gerichtet wurden. Die Sorge um die Verpflegung, wie die Amtsbezeichnung vermuten lassen würde, war wohl nur eine der

${ }^{145}$ Andre Nerrenpeck stand bereits in Diensten König Heinrichs und war schon vor ihrer zweiten Ehe für Margarethe tätig. Vgl. Archiv-Berichte aus Tirol 1, hrsg. von E. von Ottenthal-O. Redlich. Wien 1888, 420, Reg. Nr. 2375 (1341 Dezember 18, Tirol): Herzogin Margarethe verleiht Andre Nerrenpeck wegen seiner Dienste für König Heinrich und für sie selbst das von ihm bewohnte gesäss in Kematen. HHStA, Cod. B1. 126, Nr. 14. Bereits in den 1320er Jahren bezieht er regelmäßig Burghutgelder für Martinsberg bei Zirl. 1342 sind ein Andreas Nerrenpeck als Diener Ludwigs (Andre der Norrenpecken; Urkundenabschrift im HHStA, Cod. R. 55, Nr. 34, 1342 Juli 22, Innsbruck) und ein Ulrich Nerrenpeck (Ulrich der Ncerrenpecken; Urkundenabschrift ebd., Nr. 82, 1342 November 10, Nürnberg) genannt. In einem der beiden dürfen wir wohl den Küchenmeister vermuten. Ein Ulrich Noerrenpecker von Kematen wird später Jägermeister Ludwigs von Brandenburg. Moser, Urkunden (wie in Anm. 143), Nr. 74 (1358 November 27). W. Palme-Comploy, Martinsberg, in: Tiroler Burgenbuch 6 (wie in Anm. 131), 57-72, bes. 61; M. Hörmann-Weingartner, Die Burgen Tirols. Innsbruck-Wien-München ${ }^{3} 1981,116$.

146 TLA, Cod. 62, fol. $198^{\mathrm{r}}$.

147 Vgl. oben Anm. 131. Stöckl hatte mindestens eine Tochter, die ebenfalls in Diensten der Landesfürstin stand. Sie begleitete - dies ist auch der einzige Beleg - Margarethe 1354 auf einer Fahrt nach Bayern. TLA, Cod. 109, Nr. 182 (Pfandurkunde für Johann Ligsalz, Bürger von München; 1354 Oktober 7, Mittenwald. Vgl. Anm. 105). 
zahlreichen Aufgaben des magister coquine, tatsächlich scheint aber sein Aufgabengebiet nicht spezifisch geregelt gewesen zu sein ${ }^{148}$.

Der Küchenmeister Margarethes war hingegen kein Mitglied des landesfürstlichen Rates; er tritt in den Quellen kaum hervor und dürfte nur bescheidene Einflussmöglichkeiten abseits seiner Tätigkeit für die Landesfürstin gehabt haben. Immerhin beschäftigte aber auch er, gleich wie sein landesfürstliches Pendant, einen eigenen Küchenschreiber ${ }^{149}$.

\section{KÄMMERER}

Kämmerer im Hofstaat Margarethes war in den 1340er Jahren - nach 1348 ist er nicht mehr belegt - Matthias, der stets ohne Zu- und Beinamen zitiert wird. Dieser Matthias begegnet nur in den Raitbüchern, nicht jedoch in den Registern ${ }^{150}$. Ein weiterer Kämmerer Margarethes war Ortlin, der jedoch nur in zwei Urkundenabschriften (beide vom 29. Jänner 1349) erwähnt ist ${ }^{151}$, und zwar als bereits verstorben. Nennungen zu Lebzeiten gibt es keine, weshalb er, da Matthias 1347 oder 1348 offenbar ausgeschieden war, dieses Amt wohl nicht allzu lange ausgeübt haben dürfte. Ohne Namensnennung ist dann für die Jahre 1356-1358 noch einmal ein camerarius domine genannt ${ }^{152}$.

Was oben über den Küchenmeister Margarethes gesagt wurde, gilt auch für den Kämmerer. Abgesehen davon, dass auch er einen eigenen Kammerschreiber beschäftigte ${ }^{153}$, ist seine Bedeutung im Gesamtgefüge

148 Das gilt auch für die anderen Hofämter, die in der Regel von Mitgliedern des landesfürstlichen Rates besetzt waren, die von Ludwig wechselweise zu den verschiedensten Verpflichtungen herangezogen wurden. Die Unterschiede scheinen sich, zumindest nach dem Bild, das die Quellen wiedergeben, in den meisten Fällen auf die Funktionsbezeichnungen beschränkt zu haben.

${ }^{149} \mathrm{Zu}$ Heinrich, dem Küchenschreiber der Herzogin Margarethe, vgl. Anm. 176. Bereits Anna von Böhmen, die erste Frau Heinrichs von Tirol-Görz, bzw. ihr Küchenmeister hatte einen Küchenschreiber, der Sighard hieß. Hye (wie in Anm. $14), 8$.

${ }^{150}$ Im TLA, Cod. 288 (z. B. fol. 11 ${ }^{\mathrm{r}}, 1342 / 43$; fol. $42^{\mathrm{v}}$ und $43^{\mathrm{r}}, 1347 / 48$ ) und Cod. Nr. 62 (z. B. fol. 199 ${ }^{\mathrm{v}}$, 1344-1346; fol. 205, $1347 / 48$ ) ist Matthias zwischen 1342 und 1348 einige Male erwähnt. Ob er mit dem Diener Matthias (s. oben S. 102 und 104) identisch ist, lässt sich ohne nähere Angaben nicht feststellen.

151 HHStA, Cod. Bl. 129, Nr. 53 (1349 Jänner 29, ohne Ortsangabe, mit Parallelüberlieferung im BHStA, KÄA, Cod. 4841, Nr. 65), Nr. 54 (mit Parallelüberlieferung ebd., Nr. 66).

${ }^{152}$ TLA, Cod. 288 , fol. $64^{\mathrm{r}}$.

$153 \mathrm{Vgl}$. S. 114. 
des Hofes gering zu veranschlagen. Auch er war in erster Linie für Margarethe zuständig und dürfte sonst wenige Kompetenzen gehabt haben. Sein Aufgabengebiet betraf den Bereich der Finanzverwaltung. Ihm ist wohl die Verantwortung für die finanzielle Gebarung des Hofes der Herzogin übertragen gewesen ${ }^{154}$.

\section{Marschall}

Das Marschallamt im Hofstaat der Landesfürstin bekleideten Johann marstellarius $^{155}$ und Ulrich Reischauer ${ }^{156}$, nach der Datierung ihrer Erwähnungen offenbar gleichzeitig. Auch hier ist es auffällig, dass in den 1350er Jahren keine Nennungen mehr vorliegen, und es stellt sich die Frage, ob das nur an der schlechteren Quellenlage liegt. Der Marschall hatte sich um die Ausrüstung des Hofgesindes (Pferde, Verpflegung etc.) während der Reisen der Herzogin zu kümmern, kontrollierte die Pferdeknechte und war für die Quartierbeschaffung und die Organisation der Reisen zuständig ${ }^{157}$.

\section{(Mund)SchenK}

Der Mundschenk oder pincerna hatte für die Getränke zu sorgen und wurde häufig von subpincerne unterstützt, wie auch im Hofstaat Margarethes belegt ist ${ }^{158}$. Als Amtsinhaber liegt nur der Name Ullin Volrer pincerna domine vor ${ }^{159}$. Weitere Nennungen gibt es keine. Das Hofamt

154 Allgemein zu den Aufgaben eines Kämmerers Megenberg (wie in Anm. 21), I, 167-170; LackNer (wie in Anm. 4), 88f.

155 Z. B. TLA, Cod. 288, fol. $10^{\mathrm{r}}(1342 / 43)$, fol. $22^{\mathrm{v}}(1344 / 45)$, fol. $42^{\mathrm{v}}$ und fol. $43^{\mathrm{r}}$ (1347/48), sowie im Cod. Nr. 62, fol. 199 $(1344-1346)$, fol. $201^{\mathrm{v}}$ und fol. $202^{\mathrm{r}}$ (1338-1343).

156 TLA, Cod. 62, fol. $185^{\mathrm{v}}$ (1342/43) und fol. 202 $(1338-1343)$.

157 Allgemein zu den Aufgaben des Marschall Megenberg (wie in Anm. 21), I, 170f.; Spangenberg (wie in Anm. 144), 51-54; S. Kreiker, Art. Marschall. LMA 6 (1999), 324f.

${ }^{158} \mathrm{Vgl}$. Anm. 133. Allgemein zu den Aufgaben des Mundschenk Megenberg (wie in Anm. 21), I, 165-167; Rösener (wie in Anm. 13), 513.

159 TLA, Cod. 288, fol. $11^{\mathrm{v}}$ (1342/43), und BHStA, KÄA, Cod. 1155/4, Nr. 326 $/ 2$ (undatiert); weiters TLA, Cod. 129, Nr. 342 (Notiz, undatiert) ohne Funktionsbezeichnung. Möglicherweise ist Ulrich Volrer mit dem landesfürstlichen Kämmerer Jakob Volrer (oder Voldrer) verwandt, der seit 1333 Friedberg (bei Volders) innehatte. O. Trapp, Friedberg, in: Tiroler Burgenbuch 6 (wie in Anm. 131), 
eines Truchsess, der für die Speisen bei Tisch zuständig war, ist für die curia domine in den vorliegenden Quellen hingegen nicht feststellbar.

\section{TÜRHÜTER}

Türhüter war in den 1340er Jahren - später ist auch in diesem Fall kein Amtsträger mehr namentlich überliefert - Hintz der Aeblin. Er kommt mehrfach in den beiden Raitbüchern und in den Registern vor ${ }^{160}$. Aeblin war verheiratet und wird 1349 von Ludwig von Brandenburg mit einem besonderen Privileg ausgestattet. Demnach sollen Aeblin und seine Frau ohne Steuern oder ohne für Wachdienste (vigiliaciones) zahlen zu müssen, in Bozen leben können ${ }^{161}$.

Die genaue Funktion des ianitor domine lässt sich ebenfalls schwer feststellen, doch dürfte er im Gefolge Margarethes wahrscheinlich die Aufgaben eines ,Leibwächters' erfüllt haben bzw. zu anderen anfallenden Aufgaben (wie z. B. Botendienste) herangezogen worden sein ${ }^{162}$. An sich gehörten Türhüter allgemein zur Burgbesatzung. So kennen wir aus den Rechnungsbüchern zahlreiche ianitores, die auf Tiroler Burgen ihren Dienst versahen und trotz ihrer in der Diensthierarchie unteren Position einigen Einfluss gewinnen konnten - ohne ihre ,Erlaubnis‘ gab es keinen Zutritt zum Fürsten bzw. im Falle Margarethes zur Fürstin ${ }^{163}$.

247-301, bes. 248. In der Stammtafel bei Mayrhofen (wie in Anm. 98), 7, Nr. 60, scheint Ulrich nicht auf.

${ }^{160}$ Z. B. TLA, Urk. I 9560 a/4 (1342 Dezember 3, Innsbruck): Herzogin Margarethe weist Told, Richter in Passeier, an, Hintz dem Aelblein, ihrem túrhúter, der für Ludwig von Brandenburg eine Botschaft übermittelt und dabei ein Pferd verloren hat, 60 Pfund Berner für ein neues Pferd zu geben; weiters TLA, Urk. I 9560a/7 (1343 Februar 21, Meran): Ludwig von Brandenburg beauftragt Berchtold, Propst im Passeier, Albert, Schreiber von Aichach, 12 Mark Berner für einen Hengst zu geben, den Aelblein, der Türhüter der Herzogin Margarethe, bekommen hat [Ed. SPerl (wie in Anm. 60), Nr. 14, und Nr. 17]. TLA, Cod. 288, fol. $11^{\mathrm{r}}$, und Cod. Nr. 62 , fol. $187^{\mathrm{r}}$, und fol. $189^{\mathrm{r}}$ (alle 1342/43), sowie im TLA, Cod. 129, Nr. 216 (Notiz; 1346 Mai 26, Innsbruck).

161 BHStA, KÄA, Cod. 4841, Nr. 41 1/2 (1349 April 25, Bozen).

${ }_{162} \mathrm{Vgl}$. den erwähnten Botendienst in Anm. 160. In der wettinischen Frauenzimmerordnung von 1541 musste beispielsweise der Türknecht den Zugang zum Gemach der Fürstin bewachen; vgl. STReich (wie in Anm. 11), 438.

163 Allgemein zu den Aufgaben des Türhüters Lackner (wie in Anm. 4), 161f.; Konrad von Megenberg erwähnt das Amt des Türhüters nicht. 


\section{Die Schreiber der Landesfürstin}

Die generell zu beobachtende Parallelität zwischen dem Hofstaat des Landesfürsten und jenem der Landesfürstin erforderte auch eine eigene Kanzlei für Margarethe, die in erster Linie durch die Person des Notars Friedrich von Mais verkörpert wurde. Er stand zunächst in Diensten der Herzogin Eufemia, der Witwe des 1310 verstorbenen Herzogs Otto, und wurde nach deren Tod 1347 der persönliche Schreiber Margarethes, für die er schon zuvor tätig gewesen war ${ }^{164}$. Neben seiner Arbeit als Notar der Landesfürstin hatte Friedrich darüber hinaus auch andere Agenden und war in den landesfürstlichen Kanzleiapparat integriert. Man darf sich also unter der Kanzlei Margarethes keine selbständige, unabhängig von der landesfürstlichen Kanzlei arbeitende Institution vorstellen. Friedrich war lediglich personell der Herzogin zugeordnet, wie seine ,Kollegen“, der Küchenschreiber Heinrich und der Kammerschreiber Otto ${ }^{165}$.

Aufgrund seiner Tätigkeit als Rechnungsprüfer ${ }^{166}$ dürfte Friedrich innerhalb der Kanzlei eine gehobene Position eingenommen haben. Mehrfach lässt er sich als Schreiber in den Rechnungsbüchern nachweisen ${ }^{167}$, wobei er die Rechnungen jedoch nicht nur registrierte, sondern zum Teil auch für deren Inhalt verantwortlich war ${ }^{168}$. Als Vertreter der Kanzlei ist er zwar stets unter den Zeugen der Raitungen letztgereiht, dennoch, allein die Erwähnung im Kreise landesfürstlicher Räte zeugt von einigem Einfluss ${ }^{169}$.

164 Hye (wie in Anm. 14), $7 f$.

165 Vgl. unten S. 114.

166 Bis 1356 ist Friedrich in den beiden Raitbüchern als Rechnungsprüfer belegt. TLA, Cod. 288, fol. $25^{\mathrm{v}}, 39^{\mathrm{v}} 45^{\mathrm{r}}, 59^{\mathrm{r}}$, und im TLA, Cod. 62 , fol. $179^{\mathrm{v}}, 182^{\mathrm{v}}, 186^{\mathrm{v}}$, $211^{\mathrm{v}}, 214^{\mathrm{r}}, 216^{\mathrm{v}}$. In dieser Funktion wird er stets als Schreiber (notarius) bzw. auch Hofschreiber bezeichnet, nie jedoch als notarius domine.

$167 \mathrm{Zu}$ den Nachweisen vgl. Hörmann (wie in Anm. 2), 322.

168 In diesem Sinn sind wohl seine Hinweise auf die Unvollständigkeit seiner Aufzeichnungen zu verstehen: z. B. TLA, Cod. 288, fol. 55 (Raitung der Haller Salzmeier für 1352/53) als Randnotiz: Nota, quod numerus ebdomadarum vacantium non fuit expressus in racione me Frid(erico) presente; ideo non posui numerum et sic provisores predicti recesserunt nullo me informante de numero predicto; weiters TLA, Cod. 62, fol. 216 ${ }^{\mathrm{r}}$ (Raitung von 1353 Februar 3 für die Jahre 1350-1352): Nota, quod supradicta racio me Frid(erico) presente deducta fuit usque huc ut per ordinem patet sed qualiter dominus Alb(ertus) de Wolfstain, tunc provisor terre, firmavit prescriptam racionem cum relicta illius de Enna nescio, quia ad consumacionem finalis racionis non vocatus fui nec rogatus neque ulterius scripsi etc.; vgl. auch Hörmann (wie in Anm. 2), 322f.

${ }^{169}$ Neben dem Protonotar, also dem Kanzleileiter, ist aus der Kanzlei als Zeuge in den Raitungen sonst nur noch Friedrichs Bruder Albert erwähnt; vgl. dazu Hörmann (wie in Anm. 2), 310. 
Zudem beschäftigte er selbst einen eigenen Schreiber ${ }^{170}$. Neben seinem Amt als Schreiber Margarethes und den Kanzleigeschäften bekleidete Friedrich offenbar spätestens seit 1355 das Amt eines Landschreibers ${ }^{171}$, möglicherweise als Nachfolger seines 1353 verstorbenen Bruders Albert $^{172}$. Unter den namentlich bekannten Schreibern der landesfürstlichen Kanzlei weist Friedrich zusammen mit seinem Bruder, Notar Albert von Aichach, die längste Amtszeit auf. Für ihre Dienste sind beide bereits unter Heinrich von Böhmen entsprechend belohnt worden. In den Jahren nach 1321 wurden ihnen mehrfach Lehen übertragen, darunter auch der Hof Aichach unterhalb von Burg Tirol, nach dem sich vor allem Albert in der Folge nannte ${ }^{173}$. Wie sein Bruder war auch Friedrich verheiratet. Mit seiner Frau Perlinna, der Tochter des Burggrafen von Mais, hatte er sieben Kinder, deren Namen und Geburtsdaten bekannt sind, da sie Friedrich in dem von ihm angelegten „Hausbuch" notierte ${ }^{174}$.

Als notarius domine ist Friedrich sowohl in den Registern wie in den Raitbüchern vergleichsweise häufig genannt, und zwar in der Regel in

${ }^{170}$ Heinrich von Matrei, der gleichzeitig auch für Friedrichs Bruder Albert gearbeitet hat. BHStA, KÄA, Cod. 1180, Nr. $93^{\mathrm{r}} / 3$ (1348 August 19, St. Petersberg); vgl. Hörmann (wie in Anm. 2), 327f.

171 TLA, Cod. 59, Nr. 375 (1355 Jänner 26, Tirol): ... Fridr(ich) von Mayse, unserm lantschriber ...; HHStA, Cod. W. 209, Nr. 585 (Notiz; 1355 Jänner 25, Tirol; Parallelüberlieferung im BHStA, KÄA, Cod. 1155/4, Nr. 370'/2): Alle Rechnungen, Ein- und Ausgaben, die Heinrich, der Kellner von Tirol, Friedrich dem Landschreiber vorgelegt hat, wurden von diesem Stück für Stück in Raitbücher eingetragen. Friedrich oblag also offenbar die Führung der Raitprotokolle, eine Aufgabe, die den Landschreibern bereits unter Meinhard und seinen Söhnen zugekommen war; vgl. Hye (wie in Anm. 14), 13-16.

$172 \mathrm{Zu}$ Albert vor allem Hörmann (wie in Anm. 2), 309-312. Landschreiber waren in erster Linie in die Finanzverwaltung eingebunden, erreichten aber in Tirol nicht die Bedeutung, die die Landschreiber in Österreich oder in der Steiermark innehatten, wo sie zu den höchsten Landesbeamten zählten; vgl. Hye (wie in Anm. 14), 13f.; A. Dopsch, Beiträge zur Geschichte der Finanzverwaltung Österreichs im 13. Jahrhundert. Teil II: Die Organisation der Landesfürstlichen Finanzverwaltung. Das Landschreiber- und Hubmeisteramt insbesondere. MIÖG 18 (1897), 233-340; C. Lackner, Das Finanzwesen der Herzoge von Österreich in der zweiten Hälfte des 14. Jahrhunderts. Unsere Heimat 63 (1992), 284-300.

173 Hörmann (wie in Anm. 2), 309.

${ }^{174}$ L. Sснӧмach, Das älteste Tiroler Hausbuch 1335-1348. Forschungen und Mitteilungen zur Geschichte Tirols und Vorarlbergs 6 (1909), 61-66. Das Todesjahr Friedrichs ist hingegen nicht bekannt. Wir wissen nur, dass er 1356 noch gelebt hat. Nach 1356 brechen die Quellenbelege ab; vgl. Hörmanx (wie in Anm. 2), 322, und auch Heuberger (wie in Anm. 14), 79 mit Anm. 8. 
Zusammenhang mit Begünstigungen, die ihm von Seiten des Landesfürsten zuteil wurden ${ }^{175}$.

Dass ein einflussreicher, maßgeblich in die Finanzverwaltung eingebundener Notar und Kanzleibeamter auch für Margarethe die Kanzleigeschäfte erledigte, zeigt, dass diesem Posten einige Bedeutung zuerkannt werden muss.

Neben Friedrich lassen sich darüber hinaus noch weitere Schreiber feststellen, die für die Landesfürstin tätig waren: Wir haben oben bereits erwähnt, dass der Küchenmeister Margarethes einen eigenen Küchenschreiber beschäftigte, der folglich auch in Diensten Margarethes stand. Dies war bis Ende der 1340er Jahre Heinrich von Isny ${ }^{176}$, ein Geistlicher aus dem Benediktinerkloster Isny im heutigen Baden-Württemberg ${ }^{177}$. Im Sommer 1349 wird er von Ludwig von Brandenburg zum Kellner auf Tirol ernannt, ein sehr einflussreiches Amt, das für die Versorgung des landesfürstlichen Haushaltes zuständig war. Als Kellner erscheint er in der Folge häufig in den Registern und Raitbüchern ${ }^{178}$, das letzte Mal im Frühjahr $1360^{179}$. Dennoch übte er offenbar neben dieser verantwortungsvollen Tätigkeit weiterhin das Amt des Küchenschreibers aus, da er in

${ }^{175}$ Aufgrund der zahlreichen Nennungen sei hier nur eine Auswahl wiedergegeben. Weitere Belege vgl. Hörmann (wie in Anm. 2), 323. Z. B. in den Raitbüchern: TLA, Cod. 288, fol. $11^{\mathrm{v}}, 12^{\mathrm{v}}, 16^{\mathrm{r}}, 42^{\mathrm{v}}, 53^{\mathrm{v}}, 55^{\mathrm{v}}$ (hier wird Friedrich das einzige Mal mit „von Aichach“ tituliert, sonst ist „,von Mais“ gebräuchlich), fol. 62"; TLA, Cod. 62 , fol. $154^{\mathrm{r}}, 180^{\mathrm{r}}, 199^{\mathrm{v}}, 210^{\mathrm{v}}$; z. B. in den Registern: HHStA, Cod. Bl. 126, Nr. 41 (Notiz, undatiert), HHStA, Cod. R. 55, Nr. 96 $/ 2$ (Notiz; 1346 April 7, Tirol; bzw. als Urkundenabschrift im TLA, Cod. 20, Nr. 33), BHStA, KÄA, Cod. 4841, Nr. 24 $/ 1$ (1349 Jänner 12, Tirol), HHStA, Cod. Bl. 129, Nr. 45a (1352 Jänner 21, Meran).

${ }^{176}$ Heinrich, der Küchenschreiber der Herzogin Margarethe, wird mehrfach im TLA, Cod. 62, zwischen 1341 und 1348 genannt, 1346 in einer Notiz im TLA, Cod. 129, Nr. 217 (1346 Mai 25, Innsbruck); 1349 wird er von Ludwig dem Bischof Ulrich von Chur als neuer Pfarrer der Kirche St. Johann in Kortsch präsentiert. BHStA, KÄA, Cod. 4841, Nr. $27^{r}$ /3 (1349 Jänner 31, Tirol).

177 Demselben Kloster gehörte bereits Rudolf von Isny, der Protonotar der Kanzlei Meinhards und seiner Söhne, an. Heuberger (wie in Anm. 14), 143-146; Hye (wie in Anm. 14), 116-124.

178 Abgesehen von seiner amtlichen Funktion als Verwalter der Einkünfte auf Burg Tirol scheint er verschiedentlich auch als Lehensempfänger auf. So bekommt er beispielsweise in Nachfolge der beiden Notarsbrüder Albrecht und Friedrich von Aichach den Hof in Aichach zu Lehen (BHStA, KÄA, Cod. 1155/2, Nr. 359, 1356 Dezember 13, Tirol; TLA, Cod. 109, Nr. 155, 1357 November 26, Tirol).

179 BHStA, KÄA, Cod. 4843, Nr. 194 (1360 März 15, München). 
dieser Funktion immerhin noch zweimal in den 1350er Jahren genannt ist $^{180}$.

Ein weiterer Schreiber in Diensten der Landesfürstin war der Kammerschreiber Otto. Dieser war, wie der Küchenschreiber dem Küchenmeister, dem Kämmerer zugeordnet und vor allem im Bereich der Finanzverwaltung beschäftigt, wo er über die getätigten Ausgaben Buch zu führen hatte ${ }^{181}$. Otto war mit einer Frau namens Anna verheiratet und wird in den zweimaligen Erwähnungen in den Registern für seine Dienste mit einem Turm und Garten in Dorf Tirol sowie mit einem Weingarten und einem Acker in Karneid belohnt ${ }^{182}$. Häufiger erscheint sein Name in den Raitbüchern ${ }^{183}$.

Im Wesentlichen ist mit dieser Zusammenstellung der Kreis der engeren Mitglieder des Hofstaates der Margarethe umrissen. Darüber hinaus gibt es noch eine Reihe von Personen, Schneider, Köche, Apotheker, Heizer, Musiker, Sattler, Schuster, Jäger, Falkner, die ihre Dienste der Landesfürstin zur Verfügung stellten. Sie sind keine Diener im eigentlichen Sinn, auch nicht Inhaber von Hofämtern, sie gehören aber zum Personalstand und sind daher im weiteren Sinn auch zum Hofstaat zu zählen, insbesondere da ja auch Ludwig eigene Handwerker, Unterhalter, Ärzte etc. in seinen Diensten hatte. Vermischungen der Zuständigkeiten dürfte es fallweise gegeben haben.

Drei Schneider der Herzogin, Ulrich Knoblach (Ullin gen. Choflach, auch Chloblauch) $)^{184}$, magister Jakob ${ }^{185}$ und dictus Vasnacht ${ }^{186}$, haben ihren Weg in die Quellen gefunden, weiters Chúntzlinus fistulator (Pfeifer) domine $^{187}$, Jeklin der Schuster ${ }^{188}$ und Hermann, unser valchner in Pas-

1801354 in einer Urkundenabschrift für Botsch von Florenz im BHStA, KÄA, Cod. 4842, Nr. 40 (1354 März 4, Bozen) und in einer Rechnungslegung der Jahre 1357 bis 1359 im TLA, Cod. 288, fol. $72^{\text {r }}$.

181 TLA, Cod. 288, fol. 53 ${ }^{\mathrm{r}}(1350-1352)$ : ... prout continetur in libro expensarum Ottonis notarii camere domine marchionisse ... .

${ }^{182}$ HHStA, Cod. R. 55, Nr. 90 (1343 Jänner 19, Tirol), BHStA, KÄA, Cod. 1180, Nr. $94^{\mathrm{v}} / 2$ (1348 August 20, St. Petersberg), und TLA, Cod. 59, Nr. 363 (1357 Dezember 26, Tirol).

183 TLA, Cod. 288, fol. $11^{\mathrm{rv}}(1342 / 43)$, fol. $53^{\mathrm{r}}(1350 / 52)$, fol. $56^{\mathrm{v}}(1352 / 53)$; TLA, Cod. 62 , fol. $157^{\mathrm{v}}(1340 / 41)$, fol. $169^{\text {rv }}(1342)$, fol. $206^{\mathrm{v}}(1346-1348)$. Die Identität mit dem Landschreiber Otto, der vor allem in Zusammenhang mit bayerischen Betreffen genannt wird, ist nicht erwiesen; vgl. Hörmann (wie in Anm. 2), 325.

184 TLA, Cod. 288, fol. 43 (1347/48), und Cod. Nr. 62, fol. 198 $(1344 / 45)$.

${ }^{185}$ HHStA, Cod. Bl. 126, Nr. 45 (Notiz; 1343).

186 TLA, Cod. 59, Nr. 24 (1363 März 26, Tirol).

187 TLA, Cod. 62, fol. 163 (1338-1341), und fol. 173' (1342).

188 TLA, Cod. 288 , fol. $42^{\mathrm{v}}(1347 / 48)$. 
seir ${ }^{189}$; ein Heizer, Sattler, Boten und die Jäger der Landesfürstin sind ohne Namensnennung erwähnt ${ }^{190}$. Auch einen elemosinator hatte sie in ihren Diensten ${ }^{191}$. Dieser war wohl für die Ausgabe und die Verwaltung der Almosen zuständig. Mehrfach sind Apotheker genannt ${ }^{192}$, die zwar nicht explizit als apotekarii domine erscheinen, da aber allgemein die Zuständigkeit für die Apotheke bei den Fürstinnen lag ${ }^{193}$, wird wohl auch Margarethe die erste Ansprechperson und Auftraggeberin gewesen sein.

Ein persönlicher Arzt der Landesfürstin ist hingegen nicht erwähnt. Lediglich Meister Heinrich von Kempten wurde 1350 für ein Jahr von Ludwig und Margarethe gemeinsam in Diensten genommen ${ }^{194}$. Unter der Voraussetzung, dass Nennungen von Ärzten über gesundheitliche Befindlichkeiten Auskunft geben, muss Ludwig öfter als seine Gattin krank gewesen sein. Er hat zumindest zeitweise Ärzte beschäftigt ${ }^{195}$.

189 TLA, Urk. I 9560a/1 (1342 Juni 3, Tirol): Anweisung Margarethes an Heinrich den Schenken von Metz, Richter in Passeier, ihren Falkner Hermann bei seiner Tätigkeit zu unterstützen und für seine Aufwendungen aufzukommen [Ed. SPERL (wie in Anm. 60), Nr. 10].

190 TLA, Cod. 288, fol. 64 (1356-1358, haitzerio domine), fol. $72^{\mathrm{r}}(1357-1359$, sellatori domine), fol. $53^{\mathrm{v}}\left(1345-1352\right.$, nuncio domine), und fol. $57^{\mathrm{r}}(1352 / 53$, nuncio domine), fol. $22^{\mathrm{r}}$ (1344/45, venatoribus domine); TLA, Cod. 62 , fol. $169^{\mathrm{v}}$ (1342, item dedit cuidam nuncio misso in legacione domine ...).

191 TLA, Cod. 129, Nr. 287 (Notiz; 1347 September 28, ohne Ortsangabe). Auch bei Konrad von Megenberg ist dieses Amt erwähnt, das Konrad offenbar vom französischen Hof bekannt war; vgl. Drossbach (wie in Anm. 21), 26.

${ }^{192}$ Z. B. TLA, Cod. 288, fol. 23v (1342-1345): Item assignaverunt et dederunt ad expensas domini et domine magistro Jacobo apotekario et Parzifallo de Florencia marcas $L^{a}$; TLA, Cod. 62 , fol. $154^{\mathrm{r}}$ (1342): Item dedit Tegedino apotekario de Merano; fol. 169 (1342/43): Item dedit Tegedya apotekario in Merano ...; fol. $191^{\mathrm{v}}$ (1343/44): Item exsolvit Alb(er)tum de Aychach notarium curie apud Jacobum apotekarium de M(er)ano ...; fol. 202 (1338-1342): Item dedit iam in presenti racione Tswaennoni de M(er)ano apotekario ... . Vgl. weitere Beispiele aus TLA, Cod. 62 bei Stolz (wie in Anm. 92), 63. Zur Geschichte der Tiroler Apotheken vgl. F. Huter, Beiträge zur Geschichte des Apothekerwesens in Tirol. Tiroler Heimat 41 (1977), 5-43, bes. 5-9. Huter kann für Meran allerdings erst 1381 einen Apotheker nachweisen.

${ }_{193}$ Vgl. Anm. 30, und das Beispiel bei Kircher-Kannemann (wie in Anm. 28), 241.

194 BHStA, KÄA, Cod. 4841, Nr. 80r/1 (1350 Jänner 21, Tirol). Für seine Tätigkeit bekommt Meister Heinrich 30 Mark Berner.

${ }^{195}$ Z. B. TLA, Cod. 288, fol. $62^{\mathrm{r}}(1354 / 55)$ : ... pro expensis magistri Vlrici medici domini marchionis ...; BHStA, KÄA, 1155/4, fol. 370/6 (1355 Februar 18, Bozen): ... magistro Ott(on) i medico ...; BHStA, KÄA, Cod. 1155/3, pag. 366 (1357 Februar 4, Trient; mit Parallelüberlieferung als Notiz im HHStA, Cod. W. 209, Nr. 135): Ludwig von Brandenburg verleiht dem erbern weisen mann maister Ritsch(ardus), unserm artzt, wegen der Dienste, die dieser Ludwig geleistet hat 
Vergleichsweise häufig genannt sind die Köche der Margarethe. Auch sie sind nicht identisch mit den Köchen, die für Ludwig und seinen Hof gekocht haben, was bei der häufigen Abwesenheit des Landesfürsten und seiner Dienerschaft allein aus praktischen Gründen eine Notwendigkeit gewesen sein dürfte. Die meisten Zuwendungen an die Köche erfolgten de gracia, speziell an den Koch Nikolaus Griezzer ${ }^{196}$, der am häufigsten genannt ist. Neben ihm sind noch die Köche Härtlin Salzburger, Scher, Rósslin, und Kristel erwähnt ${ }^{197}$. Auch für die Köche war der Stand der Ehe kein Hindernis. So hatte Nikolaus Griezzer eine Ehefrau, ebenfalls eine Köchin, die offenbar in diesem Beruf - vielleicht als Nachfolgerin ihres Mannes? - in den 1350er Jahren auch für Margarethe tätig war ${ }^{198}$.

\section{Zusammenfassung}

Soweit es sich anhand des vorliegenden Quellenmaterials erschließen lässt, war der Hofstaat der Margarethe ,Maultasch“ ähnlich zusammengesetzt wie der Hofstaat des Landesfürsten: ein Hofmeister und eine Hofmeisterin waren ebenso vertreten wie die Hofämter und eine eigene Kanzlei mit mindestens drei Schreibern, wovon allerdings zwei dem Küchenmeister und dem Kämmerer der Landesfürstin zugeordnet waren. Eine eigene Dienerschaft, Küchenpersonal bis hinab zu einem eigenen

und noch leisten wird, auf Lebenszeit 30 Mark Einnahmen aus dem Zoll am Lueg; BHStA, KÄA, 1155/3, pag. 417/2 (1358 März 22, München): ... maister Simon dem Juden, weilent unserm artzt ...; HHStA, Cod. W. 209, Nr. 789 (1358 November 23, Tirol): ... magistro Ritschardo visico domini; BHStA, KÄA, 4843, Nr. 218a (1360 Mai 27, ohne Ortsangabe): ... pro exsolucione magistri Jacobi medici ...; vgl. weitere Beispiele Stolz (wie in Anm. 92), 62f. (demnach war Heinrich von Kempten bereits König Heinrichs Arzt, vgl. Anm. 194).

${ }^{196}$ Z. B. TLA, Cod. 288 , fol. $11^{\text {rv }}(1342 / 43)$, fol. $22^{\text {r }}(1344 / 45)$, fol. $32^{\mathrm{r}}(1346 / 47)$; weiters TLA, Cod. 62 , fol. $152^{\mathrm{r}}$ (1341), fol. 185' (1342/43): Item dedit Nicolao Griezzerio coco domine ... .

197 Z. B. TLA, Cod. 288, fol. 22 $2^{\mathrm{r}}(1344 / 45)$ : Item Hartlino Saltzpurgerio coco domine ..., fol. $43^{\mathrm{r}}(1347 / 48)$ : Item Scher coco domine ...; weiters TLA, Cod. 62, fol. 154' (1342): ... et Rósstino coco domine ..., fol. 197 (1344/45): ... Hactlino coco domine dicto Saltzpurger ..., und fol. 199 (1344-1346): ... Hartlino Saltzpurger coco domine ...; BHStA, KÄA, Cod. 4843, Nr. 265 (gestrichene Urkundenabschrift; 1360 August 26, München): Kristel, unsrer lieben gemaheln koch, bekommt von Ludwig von Brandenburg auf Lebenszeit eine wöchentliche Pfründe von zwei Pfund Berner aus dem Salzamt in Hall verliehen.

198 BHStA, 1155/3, Nr. 191/1 (Notiz; 1353 Juli 8, München): ... Griezz(er)inn coce domine .... 
Heizer gehörten ebenfalls zur curia domine, die somit vom Hof des Landesfürsten offenbar weitgehend unabhängige Strukturen aufwies. Dieser Selbständigkeit waren aber insofern Grenzen gesetzt, als de facto der Hof der Herzogin im Gesamthof integriert und die Besetzung der höheren Ämter, etwa des Hofmeisters, dem Landesfürsten vorbehalten war. Auch die Lehenvergabe an verdiente Diener und Amtsträger, die Aussteuer für die sich verehelichenden domicelle und sonstige Privilegien wurden in der Regel von Ludwig übernommen. Geldzuweisungen und Zahlungen in Naturalien sind jedoch auch von Margarethe vorgenommen worden. So sind in den Rechnungsbüchern sehr häufig auch Anweisungen per litteram domine verzeichnet ${ }^{199}$. Eine allzu strikte Trennung des, weiblichen 'Hofes von der curia domini ist darüber hinaus allein deshalb nicht anzunehmen, da nachweisbar einige der Mitglieder des Hofes der Landesfürstin auch Aufgaben des Gesamthofes übernommen hatten, wie beispielsweise der Hofmeister Gebhard von Hornbeck, der Mitglied des landesfürstlichen Rates war, oder der Schreiber Friedrich von Mais, der gleichzeitig Hofnotar und in die zentrale Finanzverwaltung eingebunden war. Auch bei der Dienerschaft wird man nicht von einer abgesonderten Gemeinschaft ausgehen können ${ }^{200}$. Dennoch, die eigene Hofhaltung bedeutete eine Separierung und schaffte für Margarethe vor allem Spielräume, die ihr einen gewissen Grad an Unabhängigkeit ermöglichten. Am ehesten sollte sich diese Selbständigkeit an der Reisetätigkeit ablesen lassen. Eine vorläufige und nur oberflächliche Analyse ihres Itinerars - soweit die Quellenlage diesbezüglich Einblicke erlaubt - zeigt jedoch, dass Margarethe zwar Reisen unternommen hat, in der Regel aber in Begleitung ihres Mannes. Zudem begann sie erst in den 1350er Jahren regelmäßig ins ,Ausland", vornehmlich nach Bayern, zu reisen. Auch diese Fahrten hat sie aber in der Regel gemeinsam mit Ludwig unternommen.

199 Die Zahlungen, die auf Anweisung der Landesfürstin getätigt wurden, betreffen nicht nur die Mitglieder ihres Hofstaates.

200 Die Diener Margarethes, Hans der Scherer (vgl. Anm. 129) und Nikolaus Hauensteiner (vgl. Anm. 120), sind beispielsweise auch als Diener Ludwigs genannt. HHStA, Cod. R. 55, Nr. 66 (1342 September 27, Innsbruck): Ludwig verleiht Nikolaus dem Hawnstain(er), unserm diener, in Ansehung von dessen Diensten zwei genannte Höfe im Stubaital nach denselben Bedingungen, die ihm bereits König Heinrich gewährt hatte. 


\section{DAs ItTINERAR DER LANDESFÜrstin}

Ein lückenloses Itinerar der Landesfürstin lässt sich schwerlich erstellen. Aufgrund der sehr knappen Formulierungen in den Rechnungsbüchern und in den Notizeinträgen der Register ist eine genaue Rekonstruktion der Reisetätigkeit Margarethes nicht möglich. Meist lässt sich kaum mehr als die Tatsache feststellen, dass Margarethe bzw. Margarethe und Ludwig samt ihrer Dienerschaft an gewissen Orten Station gemacht haben und für ihre Verpflegung gesorgt werden musste, deren Kosten meist angeführt und verrechnet werden. Selten ist hingegen vermerkt, wie lange ein Aufenthalt gedauert und wann er genau stattgefunden hat; ebenso wenig ist das Jahr der Reise immer erkennbar, da speziell in den Raitbüchern die Amtsträger in der Regel über mehrere Jahre abrechnen, ohne jeden Posten einzeln zu datieren. Bei den datierten Notizen, Urkundenabschriften und Originalurkunden ergibt sich das Problem, dass das Datum nicht unbedingt den Zeitpunkt der Reise wiedergibt, da die Ausfertigung auch nach dem Aufenthalt erfolgt sein kann. Dasselbe gilt natürlich auch für die Ausstellungsorte der Urkunden Margarethes, die ebenfalls nur bedingt für die Rekonstruktion der Reisetätigkeit herangezogen werden können. Es hat daher wenig Sinn, eine nach Jahren geordnete Aufstellung ihrer Reisestationen zu versuchen, die ohnehin nur ein unvollständiges Bild bieten kann. Die folgenden Ausführungen sollen vielmehr lediglich dem Nachweis dienen, dass auch Margarethe eine Reisetätigkeit entwickelt hat. Mit der Mobilität ihres Mannes kann sie jedoch nicht annähernd verglichen werden ${ }^{201}$.

In den 1340er Jahren beschränkte sich ihr Radius in erster Linie auf den engeren Tiroler Raum ${ }^{202}$. Aufenthalte in Rattenbergo ${ }^{203}$, Hall und

${ }^{201}$ Zum Itinerar Ludwigs vgl. Bier (wie in Anm. 40), 170-287 (bis 1351), und F. H. HaUg, Beiträge zum Itinerar Ludwigs V. des Brandenburgers. Forschungen und Mitteilungen zur Geschichte Tirols und Vorarlbergs 5 (1908), 133-144.

${ }^{202}$ Mehrfach erwähnte Aufenthalte in Meran und Umgebung werden wegen der Nähe zu Burg Tirol nicht angeführt. TLA, Cod. 288, fol. 9v, und fol. 11 ${ }^{\mathrm{r}}(1342 / 43)$ : Item dedit pro expensis domincellabus domine que remanserant infirme post introitum domine ad Athesim ... bzw. Item dedit domine intranti de valle Eni ad Athesim pro vestibus .... .

203 TLA, Cod. 129, Nr. 287 (1347 September 28, ohne Ortsangabe): Item in vigilia beati Michahel(is) familia domine veniente de Ratenberch in Hall(e) H. Chrippo et H. Fueg(er) ad cenam die sabbati ad prandium et ad cenam domino et domine venientibus et die dominico ad prandium ... (es folgt eine genaue Auflistung der einzelnen Ausgabeposten mit den jeweiligen Kosten). 
Innsbruck ${ }^{204}$, Matrei, Sterzing ${ }^{205}$, Brixen, das sie wegen eines Turniers besuchte $^{206}$, und in Klausen ${ }^{207}$ sind belegt. Neben der Brennerroute war der Weg über den Jaufen der zweite, etwas mühsamere, aber dafür von

${ }^{204}$ TLA, Cod. 62, fol. 97 (Rechnungslegung Berchtolds, Richter in Passeier, für die Jahre 1344/45): Item dedit ad expensas domini euntis ad dominam in Insprukk(a) et familiaribus domine et pro vectura camere domine in anno 1344 ...; TLA, Cod. 288, fol. 22 (1344): Item dominus Gebhardus Hornpek magister curie domine ad peticionem domini marchionis excredidit domino et domine in Insprukka in anno $X L I I I I^{\circ} \ldots$; im Zuge dieses Aufenthaltes in Innsbruck besuchte die Landesfürstin auch das Kloster St. Georgenberg bei Fiecht: ebd., fol. 22v: Item domina eundo et redeundo de monte sancti Geori in Inspr (uka) expendit libras XI; weiters ebd., fol. $47^{\mathrm{v}}$ (Rechnungslegung der Haller Salzmeier Heinrich Kripp und Heinrich Fieger für die Jahre 1348-1350): ... ad expensas domine marchionisse B(ra)nd(e)n(burgensis) in Insp(ru)ka per litteram illius de Freyb(er)ch. Item dicto Hanrich pro expensis domini et domine in Inspruka per litteram Saczenhov(er)ii marcas XXIIII. Item Joh(anni) Chirchmayr pro vino ad expensas predictas per litteram Saczenhov(er)ii marcas XXXVI. Item per litteram domine ad expensas ipsius domine factis in Hallis marcas XXIX. Item absque litteris ad expensas domine in Hallis prout liquet in libro officii in Hall(is) Veronesium marcas XXIX in ebdomeda passionis Domini in anno XLIX (= 1349).

205 TLA, Cod. 129, Nr. 229 (Notiz, undatiert, Innsbruck): Petermann von Schenna werden u. a. Auslagen verrechnet, die Ludwig und Margarethe von der Nacht des 23. auf den 24. August in Matrei gehabt haben. Ebd., Nr. 378 (Notiz; 1347 Oktober 15, Sterzing): Item ... data est littera domino Pet(er)manno de Schenn (a) pro sumptibus per dominum marchionem feria $V I^{a}$ sabbato (= Oktober 13) et die dominico (= Oktober 14) ad prandium una cum domino isto prandio et per dominam die dominico per diem et feria $I I^{a}$ (= Oktober 15) ad prandium ... (ähnlich formuliert auch in der undatierten Notiz Nr. 374, die den Aufenthaltsort Matrei nennt) und Nr. 379 (Notiz; 1347 Oktober 16, Matrei): Item data est littera domino Pet(er)man ( $n$ ) o pro sumptibus per dominum et dominam marchionissam die dominico de vespere et feria $I I^{a}$ per diem per dominam et per noctem feria $I I^{a}$ et per utriusque feria III ${ }^{a}$ die Galli ad prandium factis (abzurechnen ist die Schuldsumme über die Propstei Matrei); TLA, Cod. 62, fol. 191 (Rechnungslegung Tegens von Vilanders, Richter in Enn, für die Jahre 1344/45): Item dedit ad expensas domini in St(er)zingna ipso domino et domina euntibus in vallem Eni ...; weiters TLA, Cod. 129, Nr. 270 (Notiz; 1346 Juni 14, München): Die Haller Salzmeier werden angewiesen, zehn Fuder Salz für den Küchenbedarf der Herzogin nach Sterzing zu schicken.

206 TLA, Cod. 288, fol. 31 ${ }^{\mathrm{r}}$ (Rechnungslegung der Haller Salzmeier Heinrich Kripp und Heinrich Fieger für die Jahre 1346/47): Item dedit pro scutellis argenteis et ampulla magna et ciffo deaurato et ... missis domine marchionisse in B(ri)xinam tempore torneamenti ... .

207 TLA, Cod. 129, Nr. 86 (1346 Mai 31, Bozen): Engelmar von Vilanders werden Ausgaben rückerstattet, die er u. a. während des Aufenthaltes von Margarethe und Ludwig (domine et domini) in Brixen und Klausen gehabt hat. 
Meran aus schnellere Reiseweg Richtung Norden ${ }^{208}$. Auch ihn benützten Margarethe und ihre Begleiter, um ins Inntal bzw. vom Inntal zurück nach Burg Tirol zu kommen ${ }^{209}$. In St. Petersberg (bei Silz) wurde Station gemacht, ebenso im Passeier ${ }^{210}$. Nachweislich einmal war sie mit Ludwig in Taufers und in Thaur bei Innsbruck ${ }^{211}$. Letzterer Aufenthalt, der immerhin 12 1/2 Tage dauerte, steht in Zusammenhang mit einer Fahrt nach Innsbruck und Hall, die Margarethe offenbar anlässlich des Besuchs des Königs von Dänemark mit ihrem Gast und in Begleitung ihrer Schwester und ihrer Kinder unternommen hat ${ }^{212}$. Auch ihr Schreiber Friedrich von Mais gehörte zur Reisegruppe ${ }^{213}$. Ludwigs Anwesenheit ist bei dieser

${ }^{208}$ Vgl. O. SтоLZ, Verkehrsgeschichte des Jaufen (Schlern-Schriften 12). Innsbruck $1927,127-175$.

209 TLA, Cod. 62, fol. 197v (Rechnungslegung Berchtolds, Richter in Passeier, für die Jahre 1344/45): Item dedit ad expensas domine in Passyra proxima die sabbati post Viti per noctem et sequenti die dominico in prandio ipsa domina eunte ultra Iuvon (em) in vallem Eni pro omnibus coquine neccesariis ...; TLA, Cod. 129, Nr. 115 (Notiz; 1347 August 23, Sterzing) und Nr. 127 (gestrichene Notiz; 1347 September 3, Tirol): Haupold von Passeier werden Auslagen verrechnet, die er wegen des viertägigen Aufenthaltes Margarethes und Ludwigs im Passeier gehabt hat. Auch hier dürfte der Aufenthalt in Zusammenhang mit einer Reise über den Jaufen zu sehen sein.

210 BHStA, KÄA, Cod. 1180, Nr. 68 $/ 4$ (Notiz; 1348 August 22, Hall): Item ... data est littera domine Pet(er)mano de Schenna pro sumptibus domino et domine in monte sancti Pet(ri) factis ...; TLA, Cod. 129, Nr. 324 (Notiz; 1346 Juni 22, Meran): Iudex in Gerreut habet litteram pro marcis X, libris VII, grossis IIII ${ }^{\text {or }}$ pro expensis per dominum et dominam factis ibidem feria III ${ }^{a}$ in ebdomeda pentecostis in prandio inclusis merend(is) (Jause) et aliis expensis minutis ... .

211 Taufers: TLA, Cod. 62, fol. 191 (Rechnungslegung Tegens von Vilanders, Richter in Enn, für die Jahre 1343/44): Item ministravit ad expensas domini et domine euntibus in Tawv(er)s et redeuntibus in St(er)zinga $(m)$ pro universis coquine et aliis neccesariis ...; Thaur: TLA, Cod. 288, fol. 43 ${ }^{\mathrm{r}}$ (Rechnungslegung der Haller Salzmeier Heinrich Kripp und Heinrich Fieger für die Jahre 1347/48): Item dederunt ad expensas domine marchionisse in Taur per dies XIII sine litteris prout particulatim habuntur in libro Heinr (ici) notarii coquine .... .

${ }^{212}$ TLA, Cod. 288, fol. 42 (Rechnungslegung der Haller Salzmeier Heinrich Kripp und Heinrich Fieger für die Jahre 1347/48): Iterum dederunt ad expensis domine marchionisse et regis de Tennenmarcht pluribus vicibus in Hall(is) et in Insp (ru)ka et pro vestibus emptis domine et sorori sue et pueris suis et pro pellibus variis, marcarinis et pelliciis et vestibus domicellarum et pro phantlosis minutis et inperata pecunia ad cameram domine pluribus vicibus per quattuor litteras domine marchionisse infra predictum tempus Veronensium marcas CLXXXIX, libras VI, grossos X.

213 TLA, Cod. 288, fol. 42v (Rechnungslegung, s. oben Anm. 212): Primo Frid(erico) notario domine pro expensis in valle Eni existendo ibidem in negociis domine libras $X X$. Friedrich dürfte üblicherweise bei den Fahrten seiner Herrin dabei gewesen sein. Es ist dies aber das einzige Beispiel, das seine Anwesenheit verbürgt. 
Reise nicht belegt. Ebenfalls ohne Ludwig scheint sie 1343 Trient besucht zu haben, wobei sie auf dem Rückweg in Auer Aufenthalt nahm²14. Die Grenzen Tirols hat Margarethe in diesen Jahren nur selten überschritten. Richtung Süden wissen wir nur von einer Reise gemeinsam mit ihrem Mann nach Feltre im Jahr 1346 $6^{215}$. 1344/45 unternahm sie mit ihrer Tante Eufemia und ihrer Cousine Elisabeth von Sizilien ${ }^{216}$ eine wohl ausgedehntere Reise an den Rhein ${ }^{217}$; im Sommer 1348 besuchte sie mit Ludwig Passau $^{218}$.

Ab 1352 mehren sich die Belege für Fahrten nach Bayern. Demnach war Margarethe - allein oder mit Ludwig und einmal auch mit ihrem Sohn Meinhard - nahezu jedes Jahr in München ${ }^{219}$. Offenbar hatte der Verzicht Ludwigs von Brandenburg auf die Markgrafschaft und die Herrschaftsübernahme in Oberbayern ${ }^{220}$ auch Auswirkungen auf die fa-

214 TLA, Cod. 288, fol. 16 $6^{\mathrm{r}}$ (1342-1344): Primo ad expensas domine euntis in $T(\mathrm{ri}) \operatorname{dentu}(\mathrm{m})$... et redeuntibus in $T(\mathrm{ri}) \operatorname{dentu}(\mathrm{m})$ et ad expensas domini Ch(unradi) de Sch(en)n(a) ac aliis comitantibus domine pro universis expensis ... .

215 TLA, Cod. 129, Nr. 260 (1346 März 22, Neumarkt): Den Haller Salzmeiern werden Gelder verbucht, die Margarethe und Ludwig auf ihrer Fahrt nach Feltre verbraucht haben.

216 Diese Tochter des 1310 verstorbenen Tiroler Landesfürsten Otto heiratete 1322 König Peter von Sizilien; vgl. Riedmann (wie in Anm. 51), 436-443.

217 TLA, Cod. 288, fol. 22 $2^{\mathrm{r}}$ (aus einer Raitung der Haller Salzmeier für die Jahre 1344/45): Item dederunt ad expensas domine marchionisse et ad expensas dominarum videlicet domine Ofmye ducisse Karinth(ie) et domine de Sytzilia euntis ad Renu(m) a die Lune proxima post exaltacionem sancte crucis usque in diem $M\left(\right.$ er curii proximam sequentem in prandio videlicet per pascus $I I I I^{\circ r}$ et noctes duas ... (1344: 19. bis 21. September, oder 1345: 18. bis 20. September).

218 BHStA, KÄA, Cod. 1180, Nr. 101r/1 (1348 August 23, Rattenberg): Den Haller Salzmeiern werden u. a. Ausgaben verrechnet, die für die Reise des landesfürstlichen Paares nach Passau und zurück aufgewendet wurden. Auf dem Weg nach Passau hatte das Paar und sein Gefolge am Lueg, in Matrei, Innsbruck, Hall und Rattenberg Halt gemacht: BHStA, KÄA, Cod. 1180, Nr. 62v/2 (Notiz; 1348 Juli 10, Matrei): Den Zöllnern am Lueg werden Ausgaben Ludwigs und Margarethes isto tempore factis ibidem verrechnet. Ebd., Nr. 62v/3 (Notiz, 1348 Juli 12, Innsbruck): Petermann von Schenna werden Auslagen verrechnet, die er für Ludwig, Margarethe und famulis ipsorum in Matrei getätigt hat. Ebd., Nr. 83 1 (Notiz; 1348 Juli 14, Hall): Petermann von Schenna werden Gelder anlässlich des Aufenthaltes des landesfürstlichen Paares in Innsbruck geschuldet. Ebd., Nr. $92^{\mathrm{r}} / 2$ (1348 August 8, München): Dem Haller Salzmeier Heinrich Kripp werden Auslagen anlässlich des Aufenthaltes der Landesfürstin in Rattenberg verrechnet.

219 Bis 1361 lässt sich nur für 1359, 1360 und 1361 kein Nachweis erbringen. Dies kann aber auch an der schlechteren Quellenlage liegen.

${ }^{220} \mathrm{Zu}$ den bayerischen Erbschaftsteilungen vgl. T. STRAub, Bayern im Zeichen der Teilungen und Teilherzogtümer (1347-1450), in: Handbuch der bayerischen 
miliären Kontakte zur bayerischen Verwandtschaft. Ein Hinweis dafür dürfte auch die Begleitung des kleinen Sohnes Meinhard III. sein, den die Eltern 1353 und 1354 nach Bayern mitnahmen - möglicherweise um ihn seinen Verwandten vorzustellen ${ }^{221}$ ? Selten sind Aufenthalte außerhalb Münchens belegt; nachweisen lassen sich nur Reisen nach Freising, Regensburg und Wolfratshausen im Jahr 1353222. 1354 kam Margarethe mit Ludwig nach Ingolstadt und Nürnberg ${ }^{223}$, das gleichzeitig auch ihr nördlichstes Reiseziel war. 1353 und 1354 dürften Margarethe und ihre Familie länger in Bayern gelebt haben, weshalb auch ausgedehntere Fahrten in diesem Raum möglich waren ${ }^{224}$.

Ebenso wie Margarethe die Kontakte zu der bayerischen Verwandtschaft ab den 1350er Jahren pflegte, unterstützte sie ihren Mann auch bei der Aufnahme engerer Bindungen mit den österreichischen Herzögen, die ja ihre nächsten Verwandten waren. Eine der wichtigsten und zukunftsweisenden Abmachungen war die im Zuge der Einsetzung Herzog Albrechts II. als Pfleger in Oberbayern (Oktober 1354) getroffene Vereinbarung, Meinhard III. mit Margarethe, der Tochter des österreichi-

Geschichte: Das alte Bayern. Der Territorialstaat vom Ausgang des 12. Jahrhunderts bis zum Ausgang des 18. Jahrhunderts, hrsg. von A. KRaus. München ${ }^{2} 1988$, $196-287$, bes. $200 f ., 205-211$.

${ }^{221}$ Ausführlich dazu Hörmann (wie in Anm. 44), $320 f$.

${ }^{222}$ HHStA, Cod. W. 209, Nr. 611 (1353 Februar 8, Bozen): Ludwig von Brandenburg schuldet H. Schnellmann, Richter in Thaur, Geld für genannte Auslagen, die u. a. anlässlich des Aufenthaltes der Landesfürstin Margarethe am Freisinger Hof angefallen sind; BHStA, KÄA, Cod. 1155/3, Nr. 174/1 (1353 Juni 11, München): Ludwig von Brandenburg schuldet Gremold Drcechsel Geld für Verpflegungskosten, die er für Ludwig und Margarethe, als sie nach Regensburg ritten, ausgelegt hat; BHStA, KÄA, Cod. 1155/5, Nr. 341 $/ 2$ (1353 Oktober 20, München): Ludwig von Brandenburg schuldet seinem Getreuen Emhard dem Nertinger eine genannte Geldsumme, mit der Kosten der Landesfürstin in Wolfratshausen bezahlt worden sind.

${ }^{223}$ BHStA, KÄA, Cod. 1155/5, Nr. 340r/1 (1354 Mai 31, ohne Ortsangabe): Ludwig von Brandenburg schuldet Meinlein und Meister Albert, Wirten Ludwigs in Ingolstadt, genannte Geldsummen, die diese für Ludwig und Margarethe in Ingolstadt ausgegeben haben. Im Sommer ist durch eine neuerliche Abrechnung mit den beiden Wirten, die Anwesenheit Ludwigs und Meinhards III. in Ingolstadt belegt. Möglicherweise war Margarethe dabei. BHStA, KÄA, Cod. 1155/3, Nr. 325/2 (Notiz; 1354, feria quarta?, Ingolstadt): Ludwig schuldet Hilpold von dem Stein (de Lapide) Geld pro expensis in Nürnberg factis per dominum et dominam ... .

${ }^{224}$ So waren Margarethe und die Ihren 1353 im Frühjahr und im Herbst in Bayern. 1354 waren sie mindestens von April bis Mai in München, danach wahrscheinlich in Ingolstadt und Nürnberg. Möglich, dass sie auch den gesamten Sommer in Bayern verbrachten. Im Oktober fand dann die Rückreise über Mittenwald nach Tirol statt; vgl. Hörmann (wie in Anm. 44), 321 mit Anm. 59-61. 
schen Herzogs, zu verheiraten. Dies hatte zur Folge, dass der damals siebenjährige Meinhard zu seiner weiteren Erziehung an den österreichischen Hof nach Wien kam. Auf der Fahrt dorthin wurde er von seinen Eltern begleitet. Auch Margarethe hatte die Strapazen der weiten Reise auf sich genommen ${ }^{225}$. Erst 1357 hat sie gemeinsam mit Ludwig ihren Sohn in Wien besucht, um von dort weiter nach München zu reisen ${ }^{226}$.

Die Tiroler Orte, die als Aufenthalte für die Reisenden aufscheinen, spiegeln die Routen wider, die Margarethe und ihre Begleiter in diesen Jahren benützten ${ }^{227}$. Sowohl die Brennerroute mit den Orten Matrei, Brixen und Klausen ${ }^{228}$ als auch der Jaufen wurden weiterhin frequentiert. Nach München fuhr man über Innsbruck, Hall und Rattenberg, aber auch die Strecke über Mittenwald wurde benutzt ${ }^{229}$.

\section{Abschliessende Beobachtungen zur Frage der Herrschaftsbeteiligung}

Wie aus diesem Überblick hervorgeht, haben offenbar nur die ausgedehnteren Reisen ihren Niederschlag in den Quellen gefunden. Kürzere Reisen innerhalb des Landes scheinen dagegen nicht auf. An welchen Orten sich Margarethe bevorzugt aufhielt, ist daher schwer zu ermitteln.

${ }^{225}$ Zum Verlauf der Reise, die im Dezember 1354 stattgefunden hat, vgl. ebd., 323.

${ }^{226}$ Dazu ebd., 324.

${ }^{227}$ Allgemein zu den Verkehrswegen durch Tirol vgl. z. B. J. Riedmann, Verkehrswege, Verkehrsmittel, in: Kommunikation und Mobilität im Mittelalter. Begegnungen zwischen dem Süden und der Mitte Europas (11.-14. Jahrhundert), hrsg. von S. de Rachewiltz und J. Riedmann. Sigmaringen 1995, 61-75.

${ }^{228} 1360$ übernachtete Ludwig mit Margarethe und Meinhard viermal in Brixen und Klausen. Die Auslagen dafür hatte er Berchtold von Gufidaun zu begleichen: TLA, Urk. II 315, fol. $2^{v}$ (1360 Oktober 22, Klausen). Ebenso schuldete er Berchtold von Gufidaun für einen Aufenthalt gemeinsam mit Frau, Sohn und Schwester in Klausen und Brixen die Übernachtungs- und Verpflegungskosten: TLA, Urk. II 315, fol. $3^{\text {r }}$ (1361 Februar 20, Brixen); ed. Spert, (wie in Anm. 60), Nr. 30, 31. Wohin diese Fahrten die Familie führte, geht aus den beiden Urkunden nicht hervor.

${ }^{229}$ Z. B. war im Herbst 1353 die gesamte Familie, also Ludwig, Margarethe und ihr Sohn Meinhard III., in München. Ihre Heimreise führte sie über Weilheim, wo sie vom 26. auf den 27. Oktober übernachteten, über Garmisch und Mittenwald nach Tirol zurück. Vom 25. Oktober bis zum 5. November waren sie in Innsbruck, verbrachten die Nacht vom 5. auf den 6. November in Matrei und reisten dann weiter über Sterzing nach Brixen. Am 10. November war die Reisegruppe in Klausen, und spätestens am 20. November dürfte sie Burg Tirol erreicht haben. Die Belege dazu vgl. Hörmann (wie in Anm. 44), 320 mit Anm. 48-55. 
Auch lassen sich spezifisch verwertbare Aussagen zur Frage ihrer Selbständigkeit aus ihrem Itinerar nicht treffen.

Mehr Aufschluss über eine eventuelle Herrschaftstätigkeit oder Mitregentschaft würde man sich aus einer Analyse des vorhandenen Urkundenbestandes erwarten. Auch wenn im Rahmen dieser Arbeit eine diesbezüglich gründliche Auswertung ebenfalls nicht möglich ist, kann aus der Kenntnis des Materials dennoch festgehalten werden, dass eine aktive, kontinuierliche politische Regierungsbeteiligung zu Lebzeiten ihres Mannes nicht erkennbar ist. Wohl begegnet Margarethe fallweise als Mitausstellerin an der Seite Ludwigs - meist in Zusammenhang mit Bestätigungen älterer Privilegien -, und sie hat, wenn auch selten, Urkunden in ihrem Namen ausgestellt ${ }^{230}$; häufiger war sie an den inneren Hofgeschäften beteiligt, wie die oben bereits erwähnten Nachrichten in den Rechnungsbüchern zeigen (per litteram domine), die vornehmlich Geldanweisungen an diverse Amtsträger betreffen. Als bezeichnend für ihre geringe politische und administrative Aktivität mag die Tatsache gelten, dass sich während der zahlreichen Auslandsaufenthalte Ludwigs ihre Quellenpräsenz nicht erhöht. Ludwig hat vielmehr die Regierungsgeschäfte seinen Ratgebern bzw. vornehmlich seinem Landeshauptmann übertragen und seine Frau, die eigentliche Erbin des Landes, nicht beteiligt. Dennoch wäre es verfehlt, Margarethe politisches Desinteresse oder mangelnde Eignung vorzuwerfen. Wir wissen nicht, in welchem Ausmaß sie im Hintergrund agierte und beratend tätig wurde, und wir wissen nicht, inwiefern ihre Zurückgezogenheit im politischen Leben auf ihre eigene Entscheidung zurückgeht. Tatkraft hat sie jedenfalls mehrfach bewiesen, und mehr als andere Frauen in ihrer Position hat sie die Geschichte ihres Landes zu prägen verstanden. Die Entscheidung, ihren ersten Mann zu verstoßen, ist von ihr nicht ohne Rückhalt getroffen worden, und der Zeitpunkt war klug gewählt. Das internationale Aufsehen, das sie durch diesen Schritt hervorrief, hat sie hingenommen. Mut zeigte sie bei der Verteidigung der Burg Tirol gegen die Truppen Karls IV., während ihr Mann bei Brixen kämpfte ${ }^{231}$. Nach dem Tod Ludwigs und ihres einzigen Sohnes und Erben hat sie die Regierung übernommen und durch die Übertragung ihres Erbes an die Habsburger die Weichen für die Zukunft des Landes gestellt.

${ }^{230} \mathrm{Vgl}$. dazu die Regesten und Urkundeneditionen bei Huber (wie in Anm. 75) und die Edition ausgewählter Urkunden aus dem TLA bei Sperl (wie in Anm. 60), 52-92; soweit eine Beurteilung anhand dieser Auswahl möglich ist, hat sich Margarethe während ihrer ersten Ehe mit Johann Heinrich von Böhmen häufiger an der Ausstellung von Urkunden beteiligt.

${ }^{231}$ Am ausführlichsten sind die Ereignisse rund um die Belagerung von Burg Tirol geschildert bei HaUG (wie in Anm. 49), Bd. 3, 295-308. 